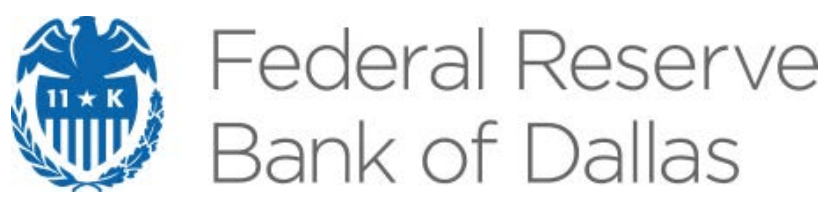

\title{
The Heterogeneous Effects of Global and National Business Cycles on Employment in U.S. States and Metropolitan Areas
}

Alexander Chudik, Janet Koech and Mark A. Wynne

Globalization Institute Working Paper 343

Research Department

https://doi.org/10.24149/gwp343

Working papers from the Federal Reserve Bank of Dallas are preliminary drafts circulated for professional comment. The views in this paper are those of the authors and do not necessarily reflect the views of the Federal Reserve Bank of Dallas or the Federal Reserve System. Any errors or omissions are the responsibility of the authors. 


\title{
The Heterogeneous Effects of Global and National Business Cycles on Employment in U.S. States and Metropolitan Areas*
}

\author{
Alexander Chudik ${ }^{\dagger}$, Janet Koech ${ }^{\ddagger}$ and Mark A. Wynne ${ }^{\S}$
}

August 22, 2018

\begin{abstract}
The growth of globalization in recent decades has increased the importance of external factors as drivers of the business cycle in many countries. Globalization affects countries not just at the macro level but at the level of states and metro areas as well. This paper isolates the relative importance of global, national and region-specific shocks as drivers of the business cycle in individual U.S. states and metro areas. We document significant heterogeneity in the sensitivity of states and metro areas to global shocks, and show that direct trade linkages are not the only channel through which the global business cycle impacts regional economies.
\end{abstract}

Keywords: Global and regional business cycles, U.S. state and metro employment fluctuations, Global VAR (GVAR) approach

JEL Classification: E24, E32, F62, F66

\footnotetext{
*We thank our discussant Jay Hyun and other participants in 93rd Western Economic Association International meetings for helpful comments. The views expressed in this paper are those of the authors and do not necessarily reflect those of the Federal Reserve Bank of Dallas or the Federal Reserve System.

${ }^{\dagger}$ Alexander Chudik, Federal Reserve Bank of Dallas, alexander.chudik@dal.frb.org

${ }^{\ddagger}$ Janet Koech, Federal Reserve Bank of Dallas

$\S_{\text {Mark A. Wynne, Federal Reserve Bank of Dallas, mark.a.wynne@dal.frb.org }}$
} 


\section{Introduction}

This paper is motivated by three observations. First, the United States economy has become a lot more globalized in recent years. One simple metric of the extent of that globalization is the ratio of the value of imports and exports of goods and services relative to total nominal GDP. Between 1985 and 2008 that ratio increased from 16.6 percent to 29.9 percent. It fell to 24.6 percent in 2009 as global trade collapsed during the Global Financial Crisis, but subsequently rebounded to more than 30 percent in 2011-2014.

Second, globalization occurs not just at the level of the aggregate U.S. economy, but in individual states and metropolitan areas. Some states and metro areas are more integrated into the global economy than others, and some states and metro areas have become more or less integrated into the global economy over time. Exports of goods amounted to 20.6 percent of Louisiana's nominal Gross State Product (GSP) in 2016, and 14.5 percent of Texas' GSP that same year. At the other extreme, exports of goods accounted for only 1.1 percent of the GSP of the District of Columbia, and 1.5 percent of the GSP of Hawaii. The biggest change in the importance of exports relative to GSP between 1996 and 2016 was for Vermont, where exports declined from 24.5 percent of GSP in 1996 to just 9.6 percent in 2016. One consequence of the greater globalization of the U.S. economy, and of the differential rates of globalization across individual states and metros, is that the global business cycle potentially plays a larger role in state and metro employment cycles than in the past.

Third, there is considerable heterogeneity in the fluctuations in economic activity across U.S. states and metros. While there is considerable co-movement of employment across U.S. states and metro areas, it is not unusual for some states to be growing while others are contracting; the same is true at the level of individual metros as well.

The question we are interested in is: to what extent are the heterogeneities in the business cycle across U.S. states and metro areas due to their different susceptibility to aggregate (global and national) shocks? We document significant differences across states and metro areas in the share of employment variation that is attributable to a global and national shocks. We then ask: what characteristics of states and metro areas can account for these differences? For example, is it the case that states or metro areas that are more dependent on international trade are more susceptible to external shocks? Or are other characteristics of states and metro areas more important? We 
will show that the channels through which global shocks impact economic activity at the state and metro area levels are more subtle than we might think.

In the remainder of this paper we review the related literature in Section 2, outline the methodology in Section 3, summarize the main findings in Section 4, and conclude in Section 5.

\section{Related literature}

There is a large literature documenting the effects of aggregate or macro (for want of a better word) shocks on disaggregate or micro entities. In international economics, we are used to thinking about the drivers of business cycles in small open economies, where the aggregate macro driver is frequently some measure of global shocks or the global business cycle. In regional economics, we are used to thinking about how national or sectoral shocks drive business cycles in regional economies, which may be regional aggregates of individual states, cities or metro areas.

One of the earliest studies examining the drivers of cyclical fluctuations in individual U.S. states was Norrbin and Schlagenhauf (1988) who decomposed fluctuations in employment at the industrial sector and regional levels into components attributable to aggregate (national), region-specific, industry-specific and idiosyncratic shocks. They focused on employment data for U.S. census regions (aggregations of U.S. states) at a quarterly frequency for the period 1954-84. They also allowed for international influences on employment fluctuations as measured by a trade-weighted average of industrial production in ten of the U.S.' largest trading partners (Germany, Japan, France, U.K., Canada, Italy, Netherlands, Belgium, Sweden and Switzerland). Norrbin and Schlagenhauf (1988) found that the national factor accounts for an average of 23.4 percent of employment fluctuations across census regions, ranging from a high of 53.7 percent in the East North Central region to a low of 7.0 percent in the West South Central region. The trade-weighted average of industrial production in foreign economies accounted for an average of 3.0 percent of employment fluctuations across census regions, ranging from a high of 6.1 percent in the East North Central region to a low of 0.5 percent in the West South Central region.

Altonji and Ham (1990) do a similar exercise for employment fluctuations in seven Canadian provinces using annual data for the period 1963-82. They use U.S. GNP to quantify the importance of external influences. Perhaps not surprisingly, they find that the largest single factor accounting 
for variation in employment growth across Canadian provinces are shocks to U.S. GNP, accounting for an average of 47 percent (ranging from a high of 61.4 percent in Ontario to a low of 37.9 percent in Alberta). The national (Canadian) shock only accounts for an average of 22.3 percent. By contrast, Prasad and Thomas (1998), using annual data for the period 1975-98 find that industry-specific shocks account for the largest fraction of the variation in employment growth across Canadian provinces, although they still find a significant role for external shocks, again proxied by shocks to U.S. GDP growth. More recently Campolieti et al. (2014) find that external and national factors play a much smaller role than the earlier research for Canadian provinces, with industry and provincial factors playing a more important role.

Kuttner and Sbordone (1997) use a similar methodology to Norrbin and Schlagenhauf (1988) and Altonji and Ham (1990) to examine the drivers of quarterly employment fluctuations in New York state over the period 1969-93. They decompose employment fluctuations into components driven by aggregate (national), industry and regional factors, but do not allow for international influences.

Clark (1998) also looked at the sources of quarterly employment fluctuations in U.S. census regions over the period 1947-90, but using a structural VAR methodology rather than the factor methodology of Norrbin and Schlagenhauf (1988). External drivers of employment fluctuations were captured using the relative price of oil (the U.S. PPI for crude petroleum deflated by the U.S. PPI for finished goods), and a (nominal) trade weighted index of seven of the U.S.' biggest trade partners (Belgium, Canada, Italy, U.K., Netherlands, Sweden and Switzerland).

Clark and Shin (2000) examine the sources of business fluctuations across a large number of countries (the U.S. plus ten European countries) and find that common (global) shocks are less important as drivers of cycles than within-country shocks.

Del Negro (2002) assesses the contributions of national, regional, state-level and idiosyncratic shocks to fluctuations in both output and consumption in U.S. states over the periods 1969-95 and 1978-95. He finds that national, regional and state-specific shocks are of about equal importance when it comes to explaining output fluctuations. However, for consumption fluctuations, statespecific shocks seem to play a more important role than national or regional shocks.

Studies of the drivers of employment fluctuations at the level of U.S. metro areas include Chang and Coulson (2001), Carlino et al. (2001) and Wall (2013). Chang and Coulson (2001) find that 
local metro shocks account for more than half of the variation in employment growth in the four cities they look at (Baltimore, Washington D.C., New York and Philadelphia) in the short run, dominating other shocks (national and sectoral). Carlino et al. (2001) also find that local (withinMSA) industry shocks explain more of the variation in employment growth than aggregate shocks in the five metro areas they look at (Chicago, Los Angeles, Oklahoma City, San Francisco and Tucson).

In the international economics literature, Norrbin and Schlagenhauf (1996) examine the importance of a common global shock as a driver of business cycles in a group of nine industrial countries, along with a nation-specific and industry-specific factor over the period 1956-92. They find that for most countries, the nation-specific factor accounts for a large amount of the forecast error variance for industrial output growth at a five-year horizon, and is the most important factor driving fluctuations. For small open economies such as Belgium and the Netherlands, the global factor is more important than the nation-specific factor. Somewhat surprisingly, they also find that the global factor is about as important as the national factor for large economies such as the U.S. and Germany.

Raddatz (2007) finds that only 11 percent of the long run variance on per capita GDP in a sample of 40 low income countries is due to external shocks, with within-country factors playing a greater role. Boschi and Girardi (2011) find that domestic and regional factors play a greater role in the fluctuations of output in the six Latin American countries that they look at. GuerronQuintana (2013) uses an estimated DSGE model to account for fluctuations in output in seven small developed countries, and finds that country-specific factors account for the bulk of the variability, with shocks to a common international factor explaining on average 10 percent.

More recently, Karadimitropoulou and León-Ledesma (2013) use a similar framework as Norrbin and Schlagenhauf (1996) to decompose value added growth into a global, nation-specific, sector specific and idiosyncratic components using data for the G7 countries over the period 1974-2004. While they look at a smaller number of countries, they include a larger number of business sectors, and estimate their model using Bayesian techniques. They also find that fluctuations are dwarfed by nation-specific factors. In contrast, Crucini et al. (2011) find that 46.7\% of the output fluctuations in G7 economies can be accounted for by global shocks, on average. 


\section{$3 \quad$ Methodology}

In this paper we rely on the Global Vector AutoRegression (GVAR) modelling framework originally proposed by Pesaran et al. (2004), and later extended by a number of contributions (see Chudik and Pesaran (2016) for an overview of the approach, and a survey of the GVAR literature.) Our GVAR model developed below differs from the mainstream GVAR models literature in that it accommodates two cross-sectional dimensions - a global (country) dimension, and a regional (state or metro area) dimension. The remainder of this section describes the data that we use (Subsection 3.1), outlines the GVAR model (Subsection 3.2), and then describes the approach for explaining state-level and metro-level heterogeneity (Subsection 3.3).

\subsection{Data}

Let output growth in country $i$ and period $t$, computed as the first difference of logarithm of real output, be denoted as $y_{i t}$, for $i=1,2, \ldots, N$ and $t=1,2, \ldots, T$, where $N$ denotes the number of countries and $T$ the number of available time periods. Our sample consists of $N=22$ advanced and emerging economies and the time dimension covers the period from the third quarter of 1980 to the fourth quarter of 2016. For convenience, and without any loss of generality, we index the U.S. as country $N$.

In addition to the individual country output growth rate for the U.S. $\left(y_{N t}\right)$, we also collected U.S. national and geographically disaggregated (state or metro area) employment growth data (computed as the first difference of logarithm of employment), denoted below as $h_{t}$ and $h_{j t}$, respectively, for $j=1,2, \ldots, n$, where $n=51$ U.S. states (including the District of Colombia) or, in the case of metro-level disaggregation, $n=415$ metro areas. ${ }^{1}$ The index $i$ is used throughout for individual countries and the index $j$ denotes the individual U.S. states or metro areas. Further information about the data is provided in Appendix A.1.

\footnotetext{
${ }^{1}$ Our metro-level disaggregation consists of all metro areas and a small number of cities and town areas available from Bureau of Labor Statistics. This includes 381 Metropolitan Statistical Areas (MSAs) (374 in the United States and 7 in Puerto Rico), 9 Metropolitan Divisions within their respective MSAs, and 25 New England City and Town Areas (NECTAs) as defined by the Office of Management and Budget (OMB).
} 


\subsection{GVAR model of output and employment}

\subsubsection{Specification and estimation of individual models}

As is common in the GVAR approach, we start with the specification of country-specific models that are augmented by cross-section averages to account for global spillovers,

$$
y_{i t}=c_{y i}+\sum_{\ell=1}^{p} \theta_{i, \ell} y_{i, t-\ell}+a_{i, 0} y_{t}^{*}+\sum_{\ell=1}^{p} a_{i, \ell} y_{t-\ell}^{*}+e_{i t}
$$

for all countries except the U.S., indexed by $i=1,2 \ldots, N-1$. For the U.S. economy, indexed as country $N$, the following cross-section-augmented VAR model is specified for the national U.S. variables collected in the vector $\mathbf{z}_{N t}=\left(y_{N t}, h_{t}\right)^{\prime}$,

$$
\mathbf{z}_{N t}=\mathbf{c}_{z i}+\sum_{\ell=1}^{p} \boldsymbol{\Theta}_{N, \ell} \mathbf{z}_{N, t-\ell}+\mathbf{a}_{N, 0} y_{t}^{*}+\sum_{\ell=1}^{p} \mathbf{a}_{N, \ell} y_{t-\ell}^{*}+\mathbf{e}_{N t},
$$

where $y_{t}^{*}=(N-1)^{-1} \sum_{i=1}^{N-1} y_{i t}$ is the global growth factor proxy, computed as a simple crosssection average of all foreign (from the perspective of U.S.) economies. ${ }^{2}$ For future reference, let $\mathbf{z}_{t}=$ $\left(y_{1 t}, y_{2 t}, \ldots, y_{N t}, h_{t}\right)^{\prime}$, and let $\mathbf{w}^{\prime}=[1 /(N-1), 1 /(N-1), \ldots, 1 /(N-1), 0,0]^{\prime}$ be the $1 \times(N+1)$ row weights vector for $y_{t}^{*}=\mathbf{w}^{\prime} \mathbf{z}_{t}$.

The U.S. state or metro employment models condition on the national as well as global aggregates, and are given by

$$
h_{j t}=c_{h j}+\sum_{\ell=1}^{p} \psi_{j, \ell} h_{j, t-\ell}+\boldsymbol{\lambda}_{j 0}^{\prime} \mathbf{z}_{N t}+\sum_{\ell=1}^{p} \boldsymbol{\lambda}_{j \ell}^{\prime} \mathbf{z}_{N, t-\ell}+\alpha_{j 0} y_{t}^{*}+\sum_{\ell=1}^{p} \alpha_{j, \ell} y_{t-\ell}^{*}+\varepsilon_{j t},
$$

for $j=1,2, \ldots, n$. We shall refer to (3) as the satellite regional model below.

The specification of the individual models in (1)-(3) resembles the standard specifications in the GVAR literature, where domestic variables are modelled as a function of their lags and contemporaneous and lagged values of cross-section (or global) averages. In the case of U.S. regional employment equations, national variables are added alongside the global averages, to capture national spillovers. A formal justification of these specifications is provided by Dees, Mauro, Pesaran,

\footnotetext{
${ }^{2}$ Whether U.S. is included in the global cross-section average $y_{t}^{*}$ or not makes little empirical difference. The simple cross-section average is almost identical to the first principal component of $\left\{y_{1 t}, y_{2 t}, \ldots, y_{N t}\right\}$.
} 
and Smith (2007) in the context of a global unobserved common factor model, and by Chudik and Pesaran (2011, hereafter CP) in the more general context of a factor-augmented high-dimensional VAR setup. Such specifications are justified asymptotically in a large $n, N$ context. $^{3}$

In addition to the conditional models in (1)-(3), we specify the following marginal model for the global aggregate $y_{t}^{*}$,

$$
y_{t}^{*}=c_{y}+\sum_{\ell=1}^{p} \rho_{\ell} y_{t-\ell}^{*}+v_{t},
$$

and we refer to $v_{t}$ as the global growth shock. It is important to highlight that (4) is not redundant even though the system (1)-(3) consists of $k=n+N+1$ equations for $k$ variables. This issue is discussed in detail in Section 4.1 of Chudik et al. (2016), who show that the system (1)-(3) alone is undetermined when the number of countries is large, and a strong unobserved common factor is present. In particular, augmentation of (1)-(3) by (4) will be necessary when a strong unobserved common factor (the global business cycle) is present and $N$ is large, whereas the augmentation is innocuous when cross-sectional dependence is not sufficiently strong. ${ }^{4}$

The individual models in (1)-(4) can be consistently estimated separately by Least Squares (LS). Conditions for consistency and asymptotic normality of the LS estimator for the individual country models (1)-(2) are established by CP, as $N, T \rightarrow \infty$ such that $N / T \rightarrow \kappa_{1}$ for some $0<\kappa_{1}<\infty$. Similarly, the asymptotic normality of the LS estimator of the individual state employment models in (3) can be established, using the same arguments, as $n, N, T \rightarrow \infty$ such that $N / T \rightarrow \kappa_{1}$ and $n / T \rightarrow \kappa_{2}$ for some $0<\kappa_{1}, \kappa_{2}<\infty$. The survey by Chudik and Pesaran (2016) provides further discussions of the GVAR approach, including the specification of individual equations, estimation and inference, and the uses of GVAR models in the literature.

\footnotetext{
${ }^{3}$ A structural (rather than econometric) macroeconomic justification for such (small open economy) specifications is provided by Chudik and Straub (2017) as an approximation of an equilibrium of a large multi-country DSGE model.

${ }^{4}$ See also Cesa-Bianchi et al. (2018) for a related discussion on the identification of global shocks in the GVAR framework.
} 


\subsubsection{GVAR solution}

Stacking (1)-(2) and substituting (4) for $y_{t}^{*}$, we obtain the following GVAR representation of $\mathbf{z}_{t}$ featuring a global (common) and country-specific (idiosyncratic) error structure,

$$
\mathbf{z}_{t}=\mathbf{c}_{z}+\sum_{\ell=1}^{p} \mathbf{G}_{z, \ell} \mathbf{z}_{t-\ell}+\mathbf{a}_{0} v_{t}+\mathbf{e}_{t}
$$

where $\mathbf{a}_{\ell}=\left(a_{1, \ell}, a_{2, \ell}, \ldots, a_{N-1, \ell}, \mathbf{a}_{N, \ell}^{\prime}\right)^{\prime}$, for $\ell=0,1, \ldots, p, \mathbf{e}_{t}=\left(e_{1 t}, e_{2 t}, \ldots, e_{N-1, t}, \mathbf{e}_{N t}^{\prime}\right)^{\prime}$, and

$$
\mathbf{G}_{z, \ell}=\mathbf{\Theta}_{\ell}+\left(\rho_{\ell} \mathbf{a}_{0}+\mathbf{a}_{\ell}\right) \mathbf{w}^{\prime}
$$

in which $\Theta_{\ell}$ is a block-diagonal matrix given by

$$
\underset{(N+1) \times(N+1)}{\boldsymbol{\Theta}_{\ell}}=\left(\begin{array}{ccccc}
\theta_{1, \ell} & 0 & 0 & \cdots & \mathbf{0}_{1 \times 2} \\
0 & \theta_{2, \ell} & 0 & & \mathbf{0}_{1 \times 2} \\
\vdots & & \ddots & & \mathbf{0}_{1 \times 2} \\
0 & 0 & & \theta_{N-1, \ell} & \mathbf{0}_{1 \times 2} \\
\mathbf{0}_{2 \times 1} & \mathbf{0}_{2 \times 1} & & \mathbf{0}_{2 \times 1} & \boldsymbol{\Theta}_{N, \ell}
\end{array}\right) .
$$

Similarly, stacking (3) and substituting (4) for $y_{t}^{*}$ and (2) for $\mathbf{z}_{N t}$ yields the following satellite GVAR representation of the $n \times 1$ vector of U.S. regional employment growth rates, collected in the vector $\mathbf{h}_{t}=\left(h_{1 t}, h_{2 t}, \ldots, h_{n t}\right)^{\prime}$, featuring an error structure composed of global, national, and regional innovations,

$$
\mathbf{h}_{t}=\mathbf{c}_{h}+\sum_{\ell=1}^{p} \boldsymbol{\Psi}_{\ell} \mathbf{h}_{t-\ell}+\sum_{\ell=1}^{p} \mathbf{G}_{h z, \ell} \mathbf{z}_{t-\ell}+\boldsymbol{\delta} v_{t}+\boldsymbol{\Lambda}_{0} \mathbf{e}_{N t}+\varepsilon_{t}
$$

where $\boldsymbol{\varepsilon}_{t}=\left(\varepsilon_{1 t}, \varepsilon_{2 t}, \ldots, \varepsilon_{n t}\right)^{\prime}$ is the $n \times 1$ vector of regional shocks, $\boldsymbol{\Lambda}_{\ell}=\left(\boldsymbol{\lambda}_{1, \ell}, \boldsymbol{\lambda}_{2, \ell}, \ldots, \boldsymbol{\lambda}_{n, \ell}\right)^{\prime}, \boldsymbol{\delta}=\boldsymbol{\alpha}_{0}+$ $\boldsymbol{\Lambda}_{0} \mathbf{a}_{N, 0}, \boldsymbol{\alpha}_{\ell}=\left(\alpha_{1, \ell}, \alpha_{2, \ell}, \ldots, \alpha_{n, \ell}\right)^{\prime}, \mathbf{\Psi}_{\ell}$, for $\ell=1, . ., p$, are $n \times n$ diagonal matrices with elements $\left\{\psi_{j, \ell}\right\}_{j=1}^{n}$ on the diagonal, and individual coefficient matrices $\mathbf{G}_{h z, \ell}$ are given by

$$
\mathbf{G}_{h z, \ell}=\boldsymbol{\Lambda}_{0}\left[\boldsymbol{\Theta}_{N, \ell} \mathbf{S}_{N}+\left(\rho_{\ell} \mathbf{a}_{N, 0}+\mathbf{a}_{N, \ell}\right) \mathbf{W}\right]+\boldsymbol{\Lambda}_{\ell} \mathbf{S}_{N}+\left(\rho_{\ell} \boldsymbol{\alpha}_{0}+\boldsymbol{\alpha}_{\ell}\right) \mathbf{W}
$$


in which $\mathbf{S}_{N}$ is $2 \times(N+1)$ selection matrix that selects $\mathbf{z}_{N t}$ from $\mathbf{z}_{t}$, namely $\mathbf{z}_{N t}=\mathbf{S}_{N} \mathbf{z}_{t}$.

The GVAR model of all of the variables collected in the vector $\boldsymbol{\xi}_{t}=\left(\mathbf{z}_{t}^{\prime}, \mathbf{h}_{t}^{\prime}\right)^{\prime}$, is given by stacking (5) and (6), and it features global, national as well as regional shocks. We use this model in a standard way to obtain a variance decomposition of regional employment fluctuations into contributions from global $(g)$, national $(n)$, and regional $(r)$ shocks. Hence, we decompose the total (tot) variance $V_{j}^{t o t}=\operatorname{Var}\left(h_{j t}\right)$ into its three components, $V_{j}^{t o t}=V_{j}^{g}+V_{j}^{n}+V_{j}^{r}$. Details on the variance-decomposition using (5)-(6) are relegated to Appendix A.2.

In addition, we compute the expected impact of a one standard error (s.e.) surprise decrease in the growth rate of global and national output on regional employment growth, which is given by the concept of the generalized impulse response function (GIRF) advanced by Koop, Pesaran, and Potter (1996) and Pesaran and Shin (1998). Details on GIRFs are relegated to Appendix A.3.

\subsection{Explaining regional heterogeneities}

To shed light on what determines the importance of the global and national business cycles for employment fluctuations in individual states or metros, we relate our findings on variance decompositions to a set of observed regional characteristics. To this end, let $\zeta_{j}=V_{j}^{g}+V_{j}^{n}$, for $j=1,2, \ldots, n$, be the share of the total variance in employment growth in region $j$ explained by the global and national shocks. We are interested in understanding if the differences across regions as measured by our estimates of $\zeta_{j}$ can be explained by a set of region-specific explanatory variables collected in the $s \times 1$ vector $\mathbf{x}_{j}$. To this end, we suppose,

$$
\zeta_{j}=\boldsymbol{\beta}^{\prime} \mathbf{x}_{j}+u_{j}
$$

where $\mathbf{x}_{j}$ is a $s \times 1$ vector of regressors (summarizing different characteristics of states or metro areas), which includes an intercept, $\boldsymbol{\beta}$ is a $s \times 1$ vector of unknown parameters, and $u_{j}$ is an error term assumed to be uncorrelated with the regressors and uncorrelated over $j$, and distributed with mean zero and variance $\sigma_{u j}^{2} \cdot{ }^{5}$ The dependent variable $\zeta_{j}$ is not directly measured. Instead, we have an estimate $\hat{\zeta}_{j}$ obtained from the GVAR model using a sample $(n, N, T)$. Let $\hat{\epsilon}_{j}$ denote the

\footnotetext{
${ }^{5}$ It is assumed that $\sigma_{u j}^{2}$ is bounded below and above in $n$.
} 
estimation error so that $\hat{\zeta}_{j}=\zeta_{j}+\hat{\epsilon}_{j}$. Hence, (7) can be written as

$$
\hat{\zeta}_{j}=\boldsymbol{\beta}^{\prime} \mathbf{x}_{j}+u_{j}^{*}, u_{j}^{*}=u_{j}+\hat{\epsilon}_{j}, \text { for } j=1,2, \ldots, n
$$

or, more compactly after stacking over $j$,

$$
\hat{\zeta}=\mathbf{X} \boldsymbol{\beta}+\tilde{\mathbf{u}},
$$

where $\hat{\boldsymbol{\zeta}}=\left(\hat{\zeta}_{1}, \hat{\zeta}_{2}, \ldots, \hat{\zeta}_{n}\right)^{\prime}$ is the $n \times 1$ vector of observations on the dependent variable, $\mathbf{X}=\left(\mathbf{x}_{1}, \mathbf{x}_{2}, \ldots, \mathbf{x}_{n}\right)^{\prime}$ is $n \times s$ matrix of observations on the regressors, and $\tilde{\mathbf{u}}=\left(\tilde{u}_{1}, \tilde{u}_{2}, \ldots, \tilde{u}_{n}\right)^{\prime}$.

Consider the LS estimator of $\boldsymbol{\beta}$ obtained by regressing $\hat{\zeta}_{j}$ on $\mathbf{x}_{j}$,

$$
\hat{\boldsymbol{\beta}}=\left(\mathbf{X}^{\prime} \mathbf{X}\right)^{-1} \mathbf{X}^{\prime} \hat{\boldsymbol{\zeta}}
$$

Substituting (8) in (9), and noting that $\tilde{\mathbf{u}}=\mathbf{u}+\hat{\boldsymbol{\epsilon}}$, we obtain

$$
\hat{\boldsymbol{\beta}}-\boldsymbol{\beta}_{0}=\left(\mathbf{X}^{\prime} \mathbf{X}\right)^{-1} \mathbf{X}^{\prime} \mathbf{u}+\left(\mathbf{X}^{\prime} \mathbf{X}\right)^{-1} \mathbf{X}^{\prime} \hat{\boldsymbol{\epsilon}}
$$

where we use $\boldsymbol{\beta}_{0}$ to denote the true value of $\boldsymbol{\beta}$. A sufficient condition for consistency of $\hat{\boldsymbol{\beta}}$ is the usual requirement on $u_{j}$ and $\mathbf{x}_{j}{ }^{6}$ and, in addition, $n^{-1} \mathbf{X}^{\prime} \hat{\boldsymbol{\epsilon}} \rightarrow p$. Using the same arguments as in Theorem 1 of Chudik and Pesaran (2011), and assuming $n, N, T \rightarrow \infty$ such that $N / T \rightarrow \kappa_{1}$ and $n / T \rightarrow \kappa_{2}$, then all of the GVAR coefficients as well as the individual elements of the standard covariance matrix estimator are $\sqrt{T}$-consistent, and therefore $\hat{\zeta}_{j}$ is also $\sqrt{T}$-consistent, namely $\hat{\epsilon}_{j}=O_{p}\left(T^{-1 / 2}\right)$. Hence, (assuming $\mathbf{x}_{j}=O_{p}(1)$ )

$$
n^{-1} \mathbf{X}^{\prime} \hat{\boldsymbol{\epsilon}}=n^{-1} \sum_{j=1}^{n} \mathbf{x}_{j} \hat{\epsilon}_{j}=n^{-1} \sum_{j=1}^{n} O_{p}\left(T^{-1 / 2}\right)=O_{p}\left(T^{-1 / 2}\right)
$$

and therefore $n^{-1} \mathbf{X}^{\prime} \hat{\boldsymbol{\epsilon}} \rightarrow p$ and $\hat{\boldsymbol{\beta}}$ is consistent. We rely on bootstrapping described in Appendix A.4 to conduct inference, allowing for heteroskedasticity of errors.

We compiled 48 state-level indicators and (due to much more limited availability) 16 metro-level

\footnotetext{
${ }^{6}$ Namely, $n^{-1} \mathbf{X}^{\prime} \mathbf{X} \rightarrow{ }_{p} \mathbf{Q}_{x x}, \mathbf{Q}_{x x}$ is invertible, and $n^{-1} \mathbf{X}^{\prime} \mathbf{u} \rightarrow{ }_{p} 0$, as $n \rightarrow \infty$.
} 
regional indicators to see what characteristics of a state or metro might account for (be correlated with) its sensitivity to global and national shocks. The state level indicators are described in Table A2. Obvious candidates include exposure to international trade as measured by the share of imports and exports in Gross State Product, the diversity of international trade links (either by product or destination), the size of the state as measured by various indicators, the composition and diversity of the states' economic structure, and measures of educational attainment (the idea being that states with more human capital might respond differently to external shocks than states with less human capital). In keeping with the agnostic spirit of our empirical exercise, we also included other variables that are less obviously directly related to a state's sensitivity to global or national shocks, such as indicators of the physical environment (heating and cooling degree days), the burden of local government debt and the homeownership rate, to highlight just a few.

Data availability at the metro area is much more limited. But again we were able to obtain measures of the share of exports in metro area output, measures of the economic size of the metro areas, measures of business dynamism, and measures of educational attainment. The full set of metro indicators that we consider is listed in Table A3.

Assuming that the number of regressors $(s)$ is fixed does not seem to be an issue when considering metro areas, where the number of regions is quite large (342 after discarding some due to limited coverage of individual MSA indicators), and the number of explanatory indicators is limited. However, this is no longer the case in the case of states, where we have 48 indicators and only 51 states. To deal with the large number of state-level indicators in comparison to the available sample size, we employ the One Covariate at a Time Multiple Testing (OCMT) selection method proposed by Chudik, Kapetanios, and Pesaran (2018) to weed out 'noise' indicators. Noise indicators are defined here as the indicators that are not part of $\mathbf{x}_{j}$ and are uncorrelated with the indicators in $\mathbf{x}_{j}$, which are also called as the 'signal' indicators. An advantage of OCMT as opposed to penalized regressions, such as Lasso, is that it seems to be very effective at selecting a pseudotrue model, which is defined to contain all signals, and no noise indicators, while possibly retaining also some of the pseudo-signals, defined as the indicators not in $\mathbf{x}_{j}$, but correlated with signals. Hence, OCMT provides a consistent selection approach (as $n, k$ are both large) of a parsimonious model that encompasses the true model, and does not feature noise indicators. 


\section{Role of the global and national business cycle in explaining the regional employment fluctuations in the U.S.}

As noted in the introduction, there is significant heterogeneity across U.S. states and metro areas in terms of where they are in the business cycle at any given point in time. It is not uncommon for some states to be growing rapidly while others are contracting. It is rare for all states to be expanding at the same time. The same is true at the level of metro areas. Figure 1 and Figure A1 in the Appendix illustrate the extent of this heterogeneity over the past thirty to forty years. Figure 1a shows that only once in the nearly forty years of data shown in the chart did employment decline in all fifty U.S. states at the same time, and that was during the recent Global Financial Crisis. At the level of metro areas (Figure 1b), we have never witnessed an episode in which employment declined in all metro areas at the same time.

However, a visual inspection of data plotted in panels A and B of Figure A1 shows that there is also significant co-movement of employment across states and metro areas, suggesting that aggregate (global or national) shocks play an important role as drivers of these fluctuations.

Table 1 reports the results of two commonly-used tests of cross-section dependence in the state and metro area data. The first is the cross section dependence (CD) test of Pesaran (2004, 2015) which is based on the average of all of the pair-wise correlations between units $i$ and $j$ : $\hat{\bar{\rho}}=2 N^{-1}(N-1)^{-1} \sum_{i=1}^{N} \sum_{j=i+1}^{N} \hat{\rho}_{i j}$ where $\hat{\rho}_{i j}$ is the correlation coefficient of cross-section unit $i$ and $j$. The test statistic $C D$ is computed as $C D=T N(N-1) \hat{\bar{\rho}} / 2$ and it is asymptotically normally distributed with unit variance, under the null of no or very limited cross-sectional dependence (see Pesaran (2015)). For our state level data we compute a value of the test statistic of $C D=220.56$. For the metro area data we compute a value of $C D=830.99$. Both values well exceed any reasonable critical values, allowing us to decisively reject the implicit null of no or sufficiently weak cross-section dependence. The second test statistic we report is the estimate of the exponent of cross-sectional dependence proposed by Bailey et al. (2016), or $\hat{\alpha}$. Values of this statistic that are close to 1 indicate a strong degree of cross-sectional dependence in the data. ${ }^{7}$ Again we cannot reject the null of a high degree of cross-section dependence in our data, at both the state and metro area levels. The strong cross-section dependence that we find here could be due to either national

\footnotetext{
${ }^{7}$ The definition of weak and strong cross-sectional dependence is provided in Chudik et al. (2011).
} 
or global factors, and it is to the investigation of these factors that we now turn.

\subsection{State-level findings}

Figure 2a shows the share of employment fluctuations in each of the fifty U.S. states and the District of Columbia that is accounted for by global, national and residual (state-specific) shocks, with the states ordered from left to right in terms of the importance of the aggregate (global and national) shocks. On average, global shocks account for 24.5 percent of the variation in employment growth across states, while national shocks account for 30.8 percent. However, there is considerable variation across states in terms of the importance of global and national shocks. Perhaps not surprisingly, global and national shocks play the smallest role in accounting for employment fluctuations in the District of Columbia. Note that global and national shocks also play a relatively small role in accounting for employment fluctuations in Louisiana, North Dakota, Alaska and West Virginia. One thing all of these states have in common is that energy (either coal or oil) accounts for an important share of economic activity in these states. To the right of the chart are states such as North Carolina, Ohio and Wisconsin, where global and national shocks together account for about four fifths of employment fluctuations.

Figure 3a shows the cumulative effect on employment growth across states after one year of a 0.5 percent negative shock to global output, with states ranked from left to right in terms of the size of the impact. The average effect across states is -0.64 percent, but again there is considerable heterogeneity. In almost all cases employment declines, and by a statistically significant amount. The exception is Alaska, where we estimate a modest increase in employment growth, but the effect is not statistically significant. Note that a 0.5 percent negative shock to global output growth has the biggest effect on employment growth in Nevada, where we estimate that employment growth declines by 1.1 percent after one year.

The cumulative one-year effect on employment growth across states of a negative national output shock of 1 percent is shown in Figure 4a. The average effect is -0.69 percent, with the biggest effect on employment growth in Nevada and the smallest effect on employment growth in Washington DC. For Wyoming, the impact is not statistically different from zero. 


\subsection{MSA-level findings}

Figure $2 \mathrm{~b}$ shows the results of a similar variance decomposition for the 415 metro areas for which we have employment data. Due to the large number of metros it is not possible to include labels, but the chart illustrates again that there is significant heterogeneity across metro areas in terms of the role played by global and national shocks as drivers of employment cycles. On average the global shock accounts for 17.9 percent of employment fluctuations across metro areas, while national shocks account for 16.0 percent. Global and national shocks play the smallest role in employment fluctuations in the New Orleans-Metairie LA metro area (where they account for just 0.05 percent and 2.60 percent of employment fluctuations respectively), and play the largest role in employment fluctuations in the Dallas-Fort Worth-Arlington TX metro area, where they account for 44.11 percent and 41.24 percent of employment fluctuations respectively.

We also calculated the effect on metro area employment growth after one year of a -0.5 percent shock to global output growth, and the results are shown in Figure 3b. On average, employment growth declines by about -0.62 percent after one year (very similar in magnitude to the average across states), but as with the state level calculations, there is considerable heterogeneity across metros. Note that for several metro areas the effect is indistinguishable from zero. The biggest effect is on employment growth in Elkhart-Goshen IN, where employment growth declines by 2.27 percentage points. The next biggest effects are on employment growth in Midland TX and Odessa TX, where employment growth declines by 1.76 and 1.62 percentage points respectively. The smallest effects are on employment growth in Bismarck ND (0.04 percentage point decline) and College Station-Bryan TX (also a 0.04 percentage point decline).

And Figure $4 \mathrm{~b}$ repeats the exercise for a -1 percent shock to national output growth. On average, employment growth declines by 0.61 percentage points after one year in response to a national output growth shock of -1 percent, but we find that in several metro areas the effect on employment growth is positive after one year, although this effect is not statistically significant. The biggest declines in employment growth in response to a national output shock after one year are in ElkhartGoshen IN (-2.19 percentage points), Las Vegas-Henderson-Paradise NV (-1.81 percentage points) and Naples-Immokalee-Marco Island FL (-1.71 percentage points). We estimate that employment growth increases after one year in response to a negative national output shock in Midland TX 
(0.80 percentage points), Odessa TX (0.52 percentage points) and Hammond LA (0.39 percentage points). The positive response of employment in Midland and Odessa to a negative national output shock probably reflects the importance of the oil industry to employment in those metros, with employment in both cities co-moving positively with oil prices while aggregate U.S. output comoves negatively with oil prices.

\subsection{Reconciling the regional differences}

How can we account for these heterogeneities in the importance of global shocks across states and metro areas? Do they simply reflect differences in the openness of individual states and metro areas, as measured by the share of exports in state or metro area economic activity? It is common practice to get back-of-the-envelope estimates of the impact of external shocks on a nation or region by simply multiplying the size of the shock by the share of exports in the region's economic activity. But perhaps other characteristics of a state or metro area matter as well? Perhaps the way in which external shocks are propagated to state and metro area employment growth rates over time depends not just on direct trade linkages, but also indirect trade linkages and other characteristics of a state or metro area's economy. For example, states or metro areas with more flexible or diversified economies may respond very differently to external shocks than states with less flexible or less diversified economies, even if exports are equally important to both.

We put together data on various characteristics of states and metro areas to try to tease out which characteristics of states and metro areas were associated with global shocks playing a large role in employment fluctuations. As we noted above, there are more indicators available for states than for metro areas. The indicators we looked at are listed in Tables A2 (for states) and A3 (for metro areas). We looked for measures of size (GSP relative to U.S. GDP), level of economic development (per capita income), industrial structure (relative importance of various sectors in state or metro GSP), demographic structure (population growth, migration), business dynamism (building permits, bankruptcies, economic freedom), intranational and international linkages (interstate flow of goods, exports and imports relative to GSP), burden of government (taxes, debt) and physical environment (heating and cooling degree days, motor vehicle miles per capita).

Table 2 reports the results of our attempt to uncover the drivers of the heterogeneities in the sensitivity to global and national shocks that we document at the state level. As noted above, given 
the abundance of indicators at the state level we used the OCMT method of Chudik, Kapetanios, and Pesaran (2018) to narrow down the list of potential explanatory variables. The top panel of the table reports the net effect coefficient estimates $\widehat{\theta}$ and the $R^{2}$ from the first stage regressions where we simply regress $\zeta_{j}$ on each indicator individually. ${ }^{8}$ The indicators are ranked in Table 2 by the size of the $R^{2}$. We find that the share of manufacturing in GSP and the share of mining in GSP can each in insolation account for a bit less than one third of the variation across states in the sensitivity to global and national shocks. Note however, that the coefficient estimates differ in sign: states with a larger manufacturing sector tend to experience employment declines when the global and national economies decline, while states with a larger mining sector (which includes oil) tend to experience employment expansions when the global and national economies decline. Note also that the highest ranked trade-related indicators are the Herfindahl index for exports by product $\left(R^{2}=0.163\right)$, followed by the share of interstate exports in GSP $\left(R^{2}=0.118\right)$ and the Herfindahl index for exports by destination $\left(R^{2}=0.060\right)$. Note that the $R^{2}$ for the share of exports in GSP is only 0.036 , comparable to that for indicators such as the number of motor vehicle registrations or the share of the population aged 18-24 without a high school diploma.

The OCMT method selects five out of the 48 variables that we start with at the state level as potentially explaining the differences in the response to global and national shocks, namely the relative size of the state (as measured by GSP relative to U.S. GDP), the importance of manufacturing (as measured by manufacturing's share of GSP), the importance of mining (as measured by the mining sector's share of GSP), the size of government (as measured by the share of government purchases in GSP) and a measure of economic dynamism or churn (as measured by the number of nonbusiness bankruptcies). Collectively, these five variables can account for just under two-thirds of the variation across states in the sensitivity of state-level employment to national and global shocks. Note that none of our trade indicators (either international or intranational) are included among the final set of explanatory variables selected by the OCMT procedure.

Table 3 shows the results for the metro areas. Since we have fewer indicators relative to the number of metro areas, we simply report the results of a cross-section regression including all of the potential explanatory variables. However, the top panel of the table shows the results from

\footnotetext{
${ }^{8}$ See Pesaran and Smith (2014) for the concept of net effect coefficients, and Chudik, Kapetanios, and Pesaran (2018) for a discussion of the role of net effect coefficients in the selection of a pseudo-true model.
} 
a first stage regression similar to that reported in Table 2 where again we rank indicators by the size of the $R^{2}$. We find that a measure of the relative size of a metro area (its GDP as a share of U.S. GDP) has the most explanatory power of any of the metro area indicators when considered in isolation for explaining the heterogeneity in sensitivity to global and national shocks across metros, followed by two indicators of the level of economic development (metro area per capita GDP and fraction of the population aged 18-24 with college education.). Exports as a share of metro area GDP explain less than 1 percent of the heterogeneity across metro areas in the sensitivity to global and national shocks.

\section{Conclusion}

This paper contributes to the existing literature on the drivers of cyclical fluctuations in economic activity at the level of individual U.S. states and metro areas using a GVAR approach extended to accommodate the global and regional cross-section dimensions. We isolate the effects of global and national shocks at the state and metro level and document differences across states and metro areas. We find that global shocks account for an average of 24.5 percent of the variation in employment growth across states and 17.9 percent of the variation in employment growth across metro areas. We also find that there is significant heterogeneity in how important global shocks are for state and metro business cycles, ranging from a low of almost no effect in Washington DC or Louisiana to accounting for more than two-thirds of employment fluctuations in North Carolina or Ohio. We see even more diversity at the level of metro areas.

We go beyond the existing literature on drivers of local business cycles to try to isolate the characteristics of state and metro area economies that may account for these differences. Somewhat surprisingly, the share of exports in state GSP does not seem to play an important role in accounting for these heterogeneities across states, although measures of state size do. The same is true for metro areas as well. This suggests that the common practice of using a measure of exports relative to GDP to assess the vulnerability of a state or metro area to global or national shocks is potentially misleading, and that the channels through which global and national shocks impact regional economies are more subtle than just direct trade linkages. 
Table 1: Summary measures of cross-sectional dependence of U.S. regional employment growth rates.

\begin{tabular}{lllll}
\hline \hline Geographic unit & $\widehat{\bar{\rho}}$ & $C D$ & $\hat{\alpha}$ & Conf. interval \\
\hline States & 0.51 & 220.56 & 0.996 & {$[0.922,1.071]$} \\
Metropolitan Areas & 0.27 & 830.99 & 1.000 & {$[0.923,1.077]$} \\
\hline \hline
\end{tabular}

Notes: $\widehat{\widehat{\rho}}$ is the average pair-wise correlation, given by $\hat{\bar{\rho}}=2 N^{-1}(N-1)^{-1} \sum_{i=1}^{N} \sum_{j=i+1}^{N} \hat{\rho}_{i j}$ where $\hat{\rho}_{i j}$ is the correlation coefficient of cross-section unit $i$ and $j$. CD is the cross-sectional dependence (CD) test statistics of Pesaran $(2004,2015) . C D=T N(N-1) \hat{\bar{\rho}} / 2$ and it is asymptotically normally distributed with unit variance, under the null of no or very limited cross-sectional dependence, see Pesaran (2015). $\hat{\alpha}$ is the estimate of the exponent of cross-sectional dependence proposed by Bailey et al. (2016). Confidence intervals in square brackets are the $95 \%$ intervals. 
Table 2: Explaining heterogeneity across U.S. states in the importance of global and national business cycles

\begin{tabular}{|c|c|c|c|c|}
\hline \multicolumn{5}{|c|}{ Net effect coefficient estimates } \\
\hline (Regressors ordered based on $R^{2}$ ) & $\hat{\theta}$ & Conf. int. & $R^{2}$ & $n$ \\
\hline Manufacturing share of GSP & 1.836 & {$[1.124,2.545]$} & 0.312 & 51 \\
\hline Mining share of GSP & -1.897 & {$[-2.463,-1.333]$} & 0.299 & 51 \\
\hline Govt. share of GSP & -2.134 & {$[-2.759,-1.527]$} & 0.231 & 51 \\
\hline GSP share of US GDP & 3.470 & {$[1.853,5.082]$} & 0.183 & 51 \\
\hline NonBusiness bankruptcies & 0.160 & {$[0.091,0.230]$} & 0.170 & 51 \\
\hline Herfindahl index (product) & -0.067 & {$[-0.097,-0.037]$} & 0.163 & 50 \\
\hline WRR trade share of GSP & 3.304 & {$[1.592,5.019]$} & 0.145 & 51 \\
\hline Real GSP per capita & 0.000 & {$[-0.001,0.000]$} & 0.142 & 51 \\
\hline Building permits & 7.931 & {$[3.354,12.331]$} & 0.121 & 51 \\
\hline Interstate exports share of GSP & 0.308 & {$[0.112,0.512]$} & 0.118 & 51 \\
\hline TPU share of GSP & -3.748 & {$[-6.881,-0.600]$} & 0.105 & 51 \\
\hline Net migration & 1.155 & {$[0.430,1.901]$} & 0.104 & 51 \\
\hline Employment of foreign MNCs & 0.486 & {$[0.171,0.800]$} & 0.098 & 51 \\
\hline Population density & -0.004 & {$[-0.005,-0.003]$} & 0.095 & 51 \\
\hline Agriculture share of GSP & -2.656 & {$[-4.613,-0.700]$} & 0.062 & 51 \\
\hline Herfindahl index (destination) & -0.063 & {$[-0.135,0.009]$} & 0.060 & 50 \\
\hline Homeownership rate & 0.767 & {$[-0.072,1.600]$} & 0.060 & 51 \\
\hline Average temperature & 0.520 & {$[-0.084,1.142]$} & 0.056 & 48 \\
\hline Imports share of GSP & 0.402 & {$[-0.129,0.925]$} & 0.056 & 51 \\
\hline Services share of GSP & 2.669 & {$[0.353,4.981]$} & 0.055 & 51 \\
\hline State tax rates & 3.405 & {$[-0.554,7.440]$} & 0.050 & 51 \\
\hline FIRE share of GSP & 0.762 & {$[-0.184,1.718]$} & 0.046 & 51 \\
\hline Median home values & -0.059 & {$[-0.135,0.022]$} & 0.045 & 51 \\
\hline Heating degree days & -0.002 & {$[-0.004,0.001]$} & 0.044 & 51 \\
\hline Average precipitation & 3.161 & {$[-1.131,7.253]$} & 0.044 & 48 \\
\hline Population growth & 5.446 & {$[0.358,10.286]$} & 0.043 & 51 \\
\hline Education $(25+)$ no highsch & 2.377 & {$[0.283,4.400]$} & 0.042 & 51 \\
\hline Economic freedom index & 5.833 & {$[-0.964,12.659]$} & 0.041 & 50 \\
\hline Interstate imports share of GSP & 0.218 & {$[-0.066,0.500]$} & 0.039 & 51 \\
\hline MVehicle registrations & -0.029 & {$[-0.080,0.022]$} & 0.036 & 51 \\
\hline Education (18-24) no highsch & 1.233 & {$[-0.435,2.868]$} & 0.036 & 51 \\
\hline Exports share of GSP & 1.028 & {$[-0.606,2.657]$} & 0.036 & 51 \\
\hline Per capita personal income & -0.564 & {$[-1.523,0.370]$} & 0.024 & 51 \\
\hline Education $(25+)$ college & -0.406 & {$[-1.359,0.555]$} & 0.015 & 51 \\
\hline Taxes per capita & 2.210 & {$[-3.799,7.948]$} & 0.010 & 51 \\
\hline Credit card debt per capita & -4.312 & {$[-15.982,7.018]$} & 0.010 & 51 \\
\hline Poverty rates & -0.526 & {$[-1.908,0.865]$} & 0.009 & 51 \\
\hline Employment tied to exports & 0.867 & {$[-2.043,3.848]$} & 0.008 & 50 \\
\hline Government debt share of GSP & 0.491 & {$[-0.988,1.953]$} & 0.008 & 51 \\
\hline Education(18-24) college & -0.501 & {$[-2.190,1.195]$} & 0.008 & 51 \\
\hline Rate of natural increase & -0.464 & {$[-2.277,1.369]$} & 0.004 & 51 \\
\hline Business bankruptcies & -0.212 & {$[-1.291,0.851]$} & 0.002 & 51 \\
\hline Auto debt per capita & -1.673 & {$[-12.610,9.486]$} & 0.002 & 51 \\
\hline Prisoners per capita & -0.387 & {$[-4.307,3.530]$} & 0.001 & 50 \\
\hline Mortgage debt per capita & 0.052 & {$[-0.509,0.614]$} & 0.001 & 51 \\
\hline MVehicle miles traveled per capita & 0.215 & {$[-3.378,3.895]$} & 0.000 & 51 \\
\hline Cooling degree days & 0.000 & {$[-0.006,0.006]$} & 0.000 & 51 \\
\hline Construction share of GSP & -0.167 & {$[-6.389,6.083]$} & 0.000 & 51 \\
\hline \multicolumn{5}{|c|}{ CS regression for variables selected by OCMT } \\
\hline & $\hat{\beta}$ & Conf. int. & & \\
\hline GSP share of US GDP & 2.587 & {$[1.658,3.534]$} & & \\
\hline Manufacturing share of GSP & 0.802 & {$[0.139,1.469]$} & & \\
\hline Mining share of GSP & -1.265 & {$[-1.931,-0.597]$} & & \\
\hline Govt. share of GSP & -0.794 & {$[-1.483,-0.116]$} & & \\
\hline NonBusiness bankruptcies & 0.095 & {$[0.051,0.141]$} & & \\
\hline adjusted $R^{2}$ & 0.613 & & & \\
\hline$n$ & 51 & & & \\
\hline
\end{tabular}

Notes: The dependent variable is the variance share (in \%) of employment fluctuations explained by global and national shocks. Confidence intervals in square brackets are the $90 \%$ intervals. A constant is included in all regressions (not reported). Definitions of individual regressors and their regional availability is provided in Appendix Table A2. The OCMT selection procedure is applied to all state-level indicators using critical value function with $p=10 \%, \delta=1$ and $\delta^{*}=2$. 
Table 3: Explaining heterogeneity across U.S. metros in the importance of global and national business cycles

\begin{tabular}{|c|c|c|c|c|}
\hline \multicolumn{5}{|c|}{ Net effect coefficient estimates } \\
\hline (Regressors ordered based on $R^{2}$ ) & $\hat{\theta}$ & Conf. int. & $R^{2}$ & $n$ \\
\hline GDP share of US GDP & 12.030 & {$[6.691,17.363]$} & 0.215 & 365 \\
\hline Real GSP per capita & 0.617 & {$[0.473,0.761]$} & 0.147 & 364 \\
\hline Education (18-24) college & 1.954 & {$[1.524,2.390]$} & 0.135 & 383 \\
\hline Education $(25+)$ college & 0.608 & {$[0.414,0.798]$} & 0.080 & 383 \\
\hline Poverty rates & -0.759 & {$[-0.923,-0.585]$} & 0.072 & 372 \\
\hline Per capita personal income & 0.697 & {$[0.344,1.039]$} & 0.055 & 365 \\
\hline Net migration & 0.477 & {$[0.226,0.729]$} & 0.042 & 365 \\
\hline Median home values & 0.033 & {$[0.019,0.049]$} & 0.029 & 361 \\
\hline Building permits & -1.340 & {$[-2.005,-0.674]$} & 0.017 & 364 \\
\hline Population growth & 1.802 & {$[0.245,3.357]$} & 0.013 & 374 \\
\hline NonBusiness bankruptcies & -0.025 & {$[-0.049,-0.002]$} & 0.007 & 365 \\
\hline Education (18-24) no highsch & 0.200 & {$[-0.051,0.451]$} & 0.004 & 383 \\
\hline Education $(25+)$ no highsch & -0.292 & {$[-0.633,0.052]$} & 0.003 & 383 \\
\hline Real GDP growth & 0.827 & {$[-0.442,2.149]$} & 0.003 & 365 \\
\hline Exports share of GDP & 0.057 & {$[-0.104,0.218]$} & 0.001 & 342 \\
\hline Business bankruptcies & -0.279 & {$[-1.322,0.769]$} & 0.000 & 364 \\
\hline \multicolumn{5}{|c|}{ Full CS regression } \\
\hline & $\hat{\beta}$ & Conf. int. & & \\
\hline Exports share of GDP & 0.134 & {$[-0.017,0.281]$} & & \\
\hline Real GDP growth & -2.124 & {$[-3.731,-0.494]$} & & \\
\hline GDP share of US GDP & 7.244 & {$[2.939,11.519]$} & & \\
\hline Real GSP per capita & 0.477 & {$[0.206,0.738]$} & & \\
\hline Population growth & -0.845 & {$[-2.781,1.079]$} & & \\
\hline Net migration & 0.754 & {$[0.442,1.064]$} & & \\
\hline Business bankruptcies & 1.367 & {$[0.254,2.483]$} & & \\
\hline NonBusiness bankruptcies & 0.028 & {$[-0.002,0.058]$} & & \\
\hline Building permits & -0.852 & {$[-1.692,-0.021]$} & & \\
\hline Education (18-24) no highsch & 0.470 & {$[0.075,0.860]$} & & \\
\hline Education (18-24) college & 1.590 & {$[0.699,2.470]$} & & \\
\hline Education $(25+)$ no highsch & 0.505 & {$[-0.134,1.150]$} & & \\
\hline Education $(25+)$ college & 0.022 & {$[-0.331,0.386]$} & & \\
\hline Per capita personal income & -0.405 & {$[-0.788,-0.007]$} & & \\
\hline Median home values & -0.024 & {$[-0.043,-0.004]$} & & \\
\hline Poverty rates & -0.798 & {$[-1.279,-0.322]$} & & \\
\hline \multirow[t]{2}{*}{ adjusted $R^{2}$} & 0.340 & & & \\
\hline & 335 & & & \\
\hline
\end{tabular}

Notes: The dependent variable is the variance share (in \%) of employment fluctuations explained by global and national shocks. Confidence intervals in square brackets are the $90 \%$ intervals. A constant is included in all regressions (not reported). Definitions of individual regressors and their regional availability is provided in Appendix Table A3. 
Figure 1: Yearly employment growth range across U.S. states (A) and U.S. metropolitan areas (B)

A. U.S. states

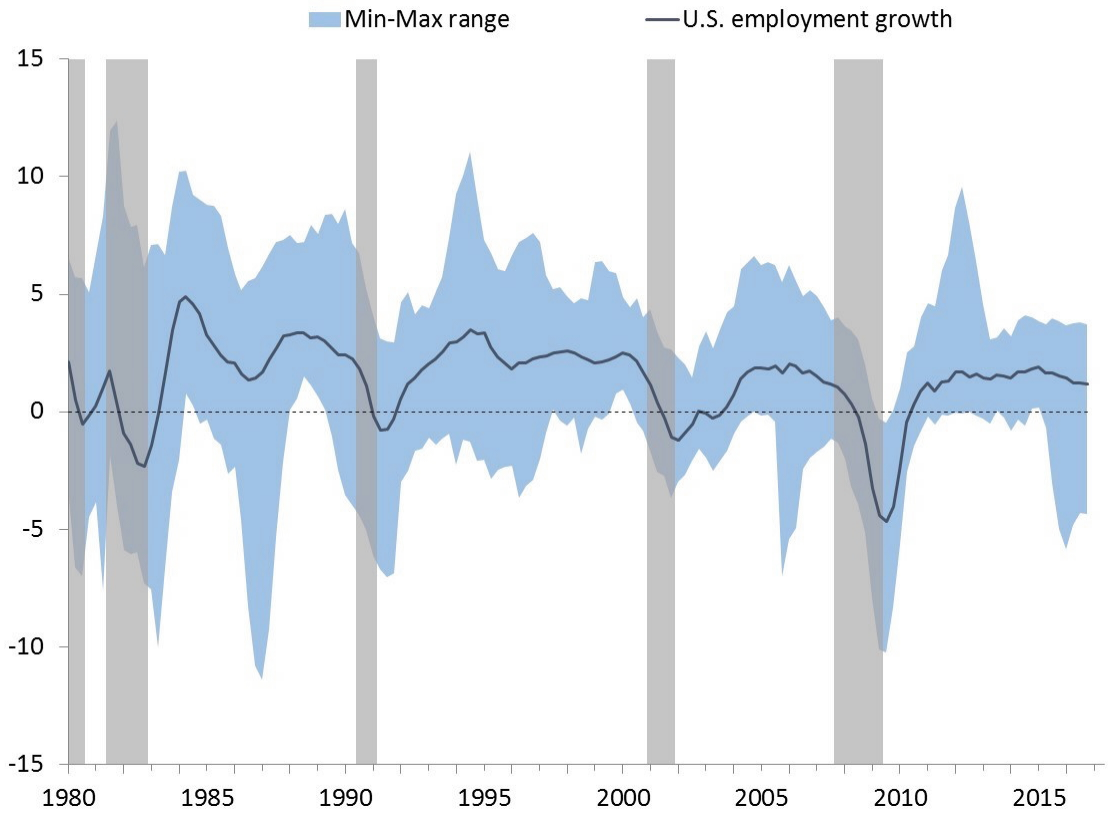

B. U.S. metropolitan areas

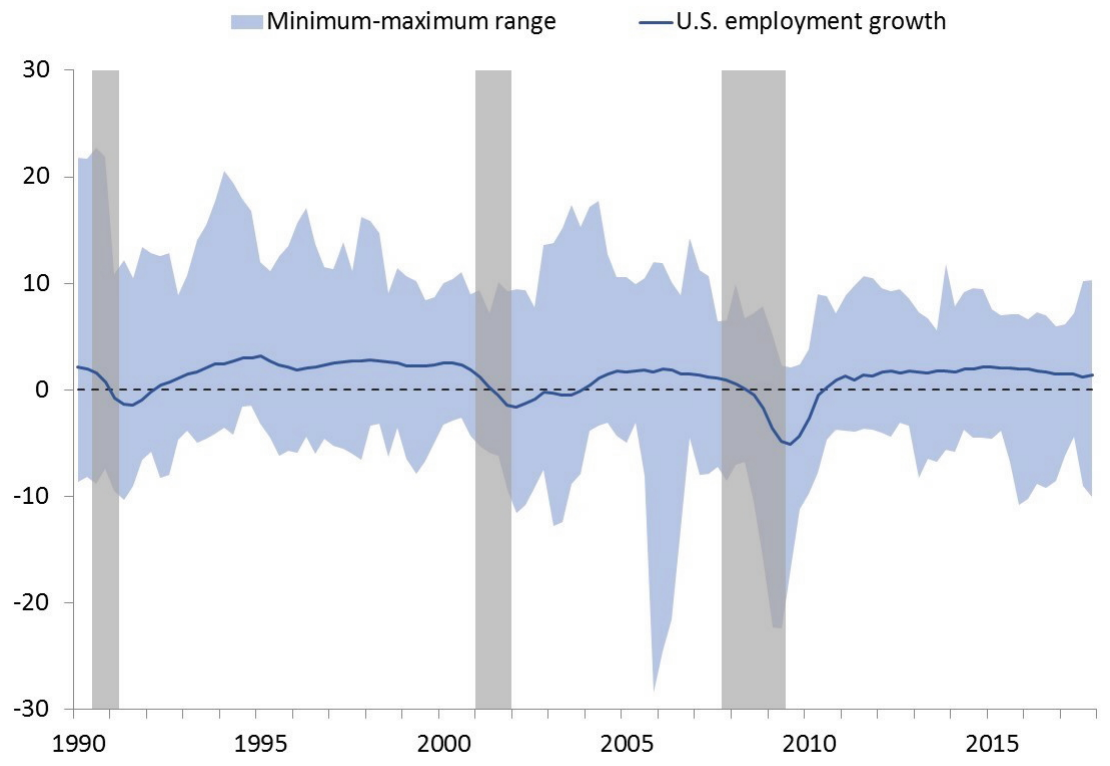

Notes: Employment fluctuations are computed as year-over-year growth of quarterly nonfarm payroll employment. Shaded bars indicate U.S. recessions. 
Figure 2: Share of U.S. states' employment variation explained by global, national and residual shocks

A. U.S. states

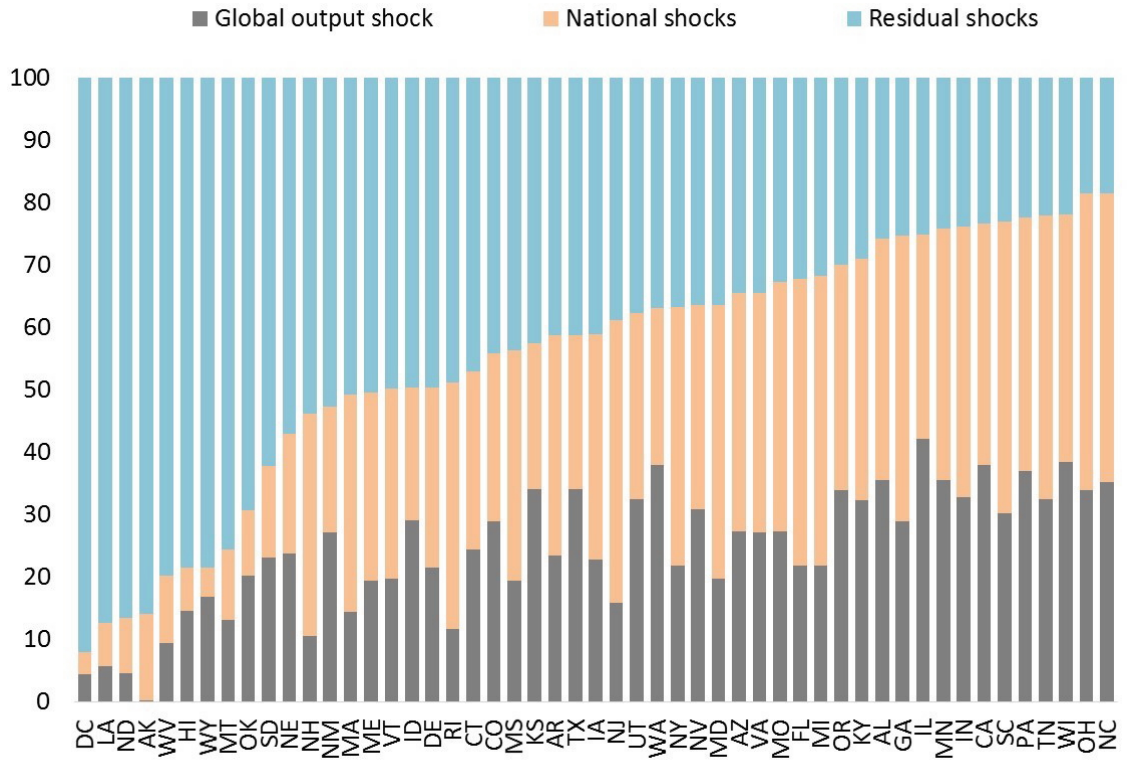

B. U.S. metropolitan areas

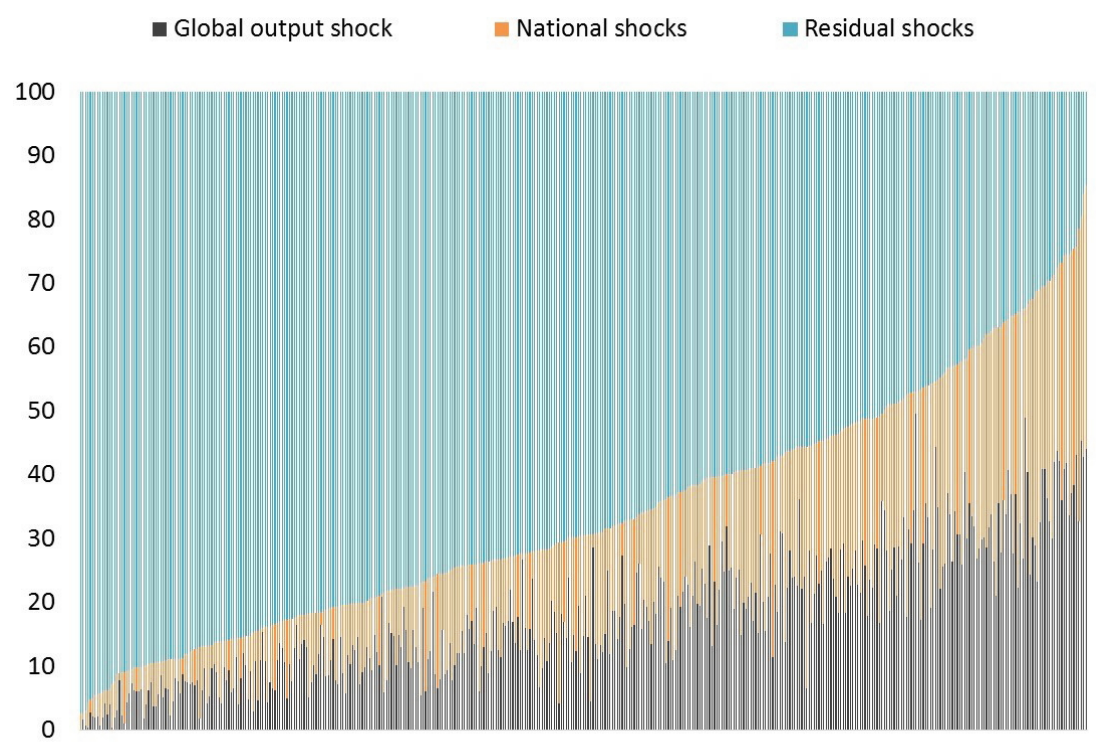

Notes: This figure shows the decomposition of the total variance of regional employment fluctuations to contributions from global (black bars), national (orange bars), and regional/residual (blue bars) shocks, based on the GVAR model outlined in Section 3.2. The average share of the variation in employment growth at the state level that is accounted for by the different shocks is 24.5 percent for the global shock, 30.8 percent for the national shock and 44.7 percent for the residual shock. At the MSA level, the average contributions are 17.9 percent for the global shock, 16.0 percent for the national shock and 66.1 percent for the residual shock. 
Figure 3: Effect of a $0.5 \%$ negative shock to foreign output on U.S. states and metro areas employment levels one year after the shock (deviations from baseline)

A. U.S. states

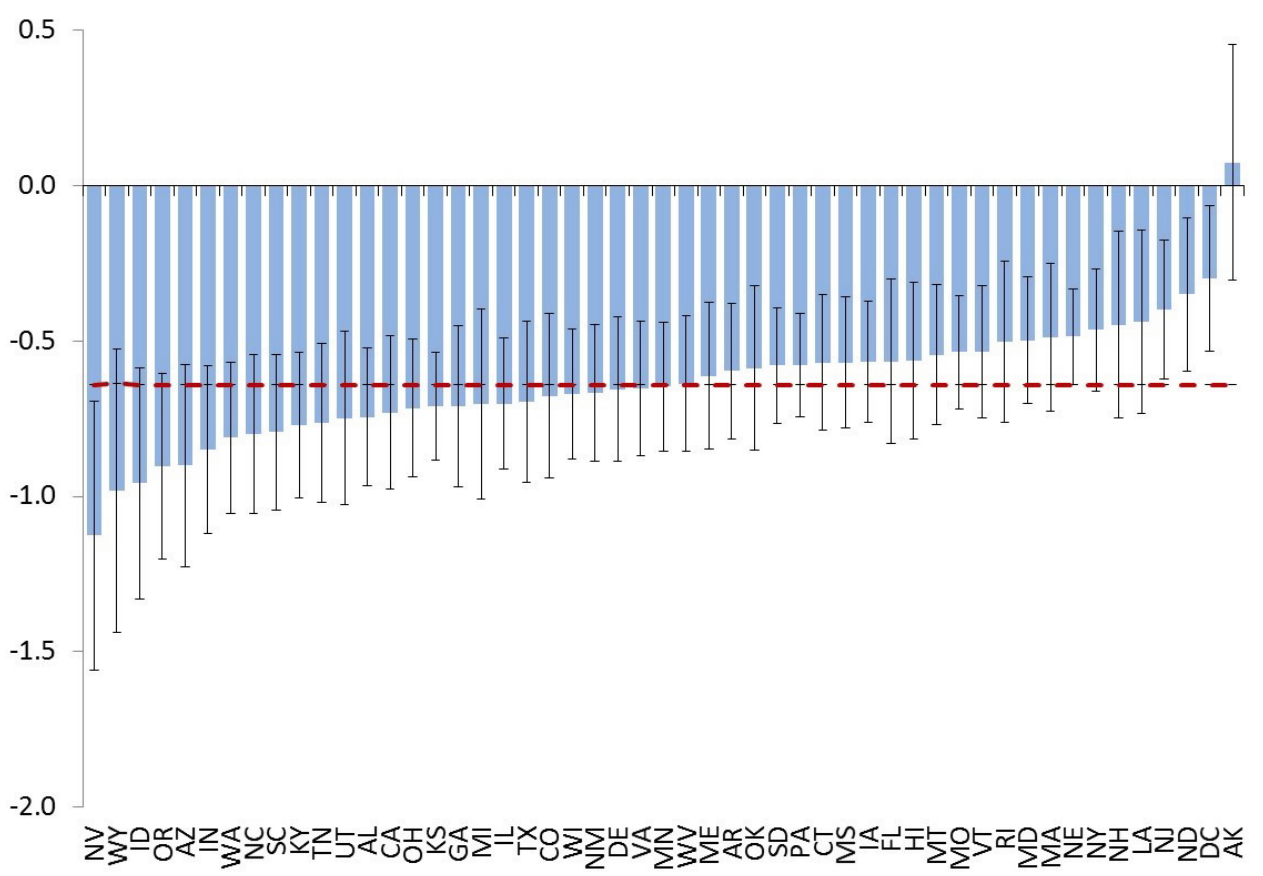

B. U.S. metropolitan areas

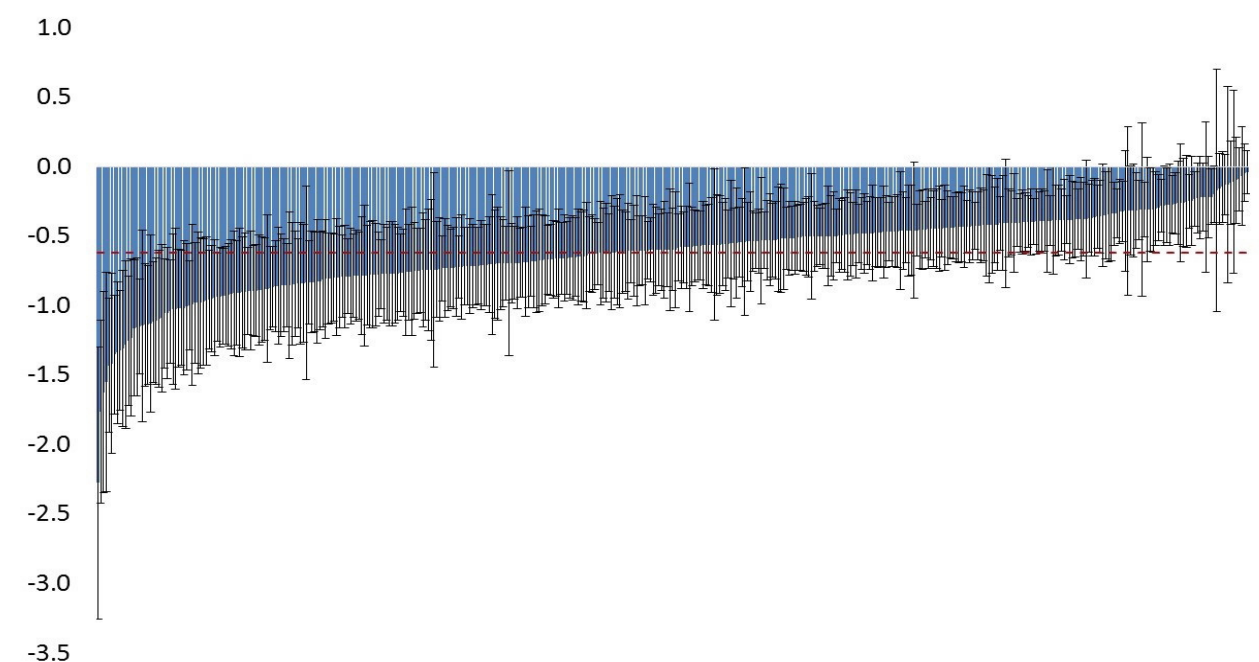

Notes: Figures show the cumulative effects on employment growth in U.S. states and metro areas of a negative shock to global output growth. A one year cumulative impact on national employment growth is -0.65 percent for states and -0.66 percent for MSAs. The 0.5 percentage point magnitude of the shock is relatively large given that the sample standard deviation (a statistical measure of a standard size of a shock) is 0.36 percentage points in states GVAR model and 0.37 percentage points in MSA GVAR model. The red dashed line shows the average cumulative impact on state employment (-0.64 percent) and MSA employment (-0.62 percent). 
Figure 4: Effect of a $1 \%$ negative shock to U.S. output on U.S. states and metro areas employment levels one year after the shock (deviations from baseline)

A. U.S. states

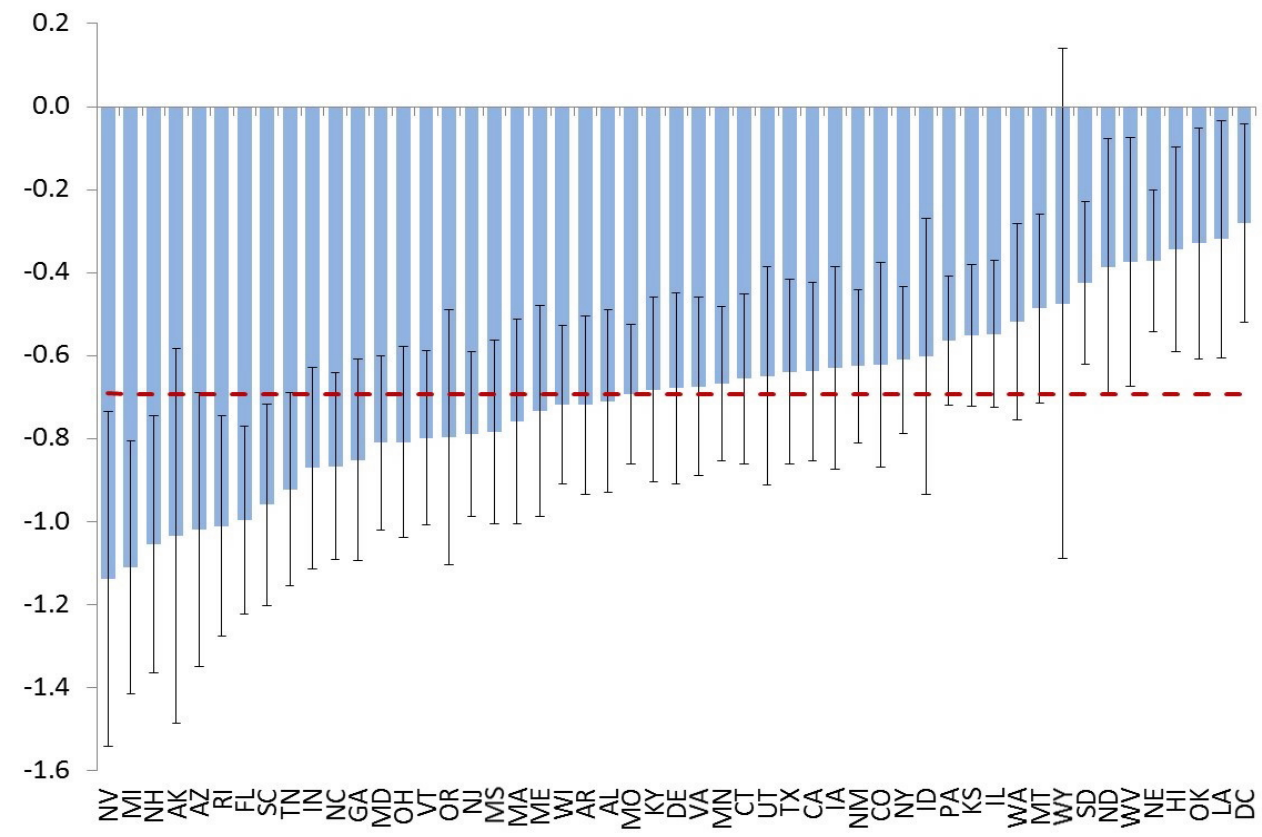

B. U.S. metropolitan areas

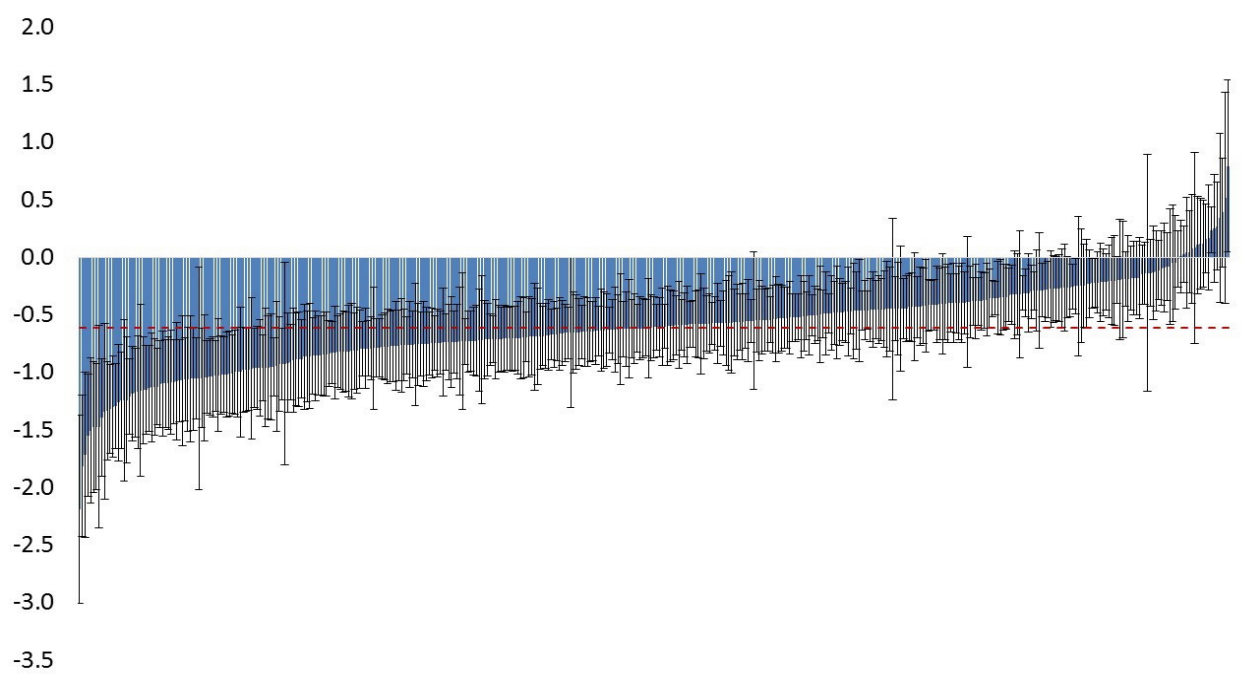

Notes: Figures show the one year cumulative impact on employment growth in U.S. states and MSAs of a 1 percentage point negative shock to U.S. output growth. The effect on national employment growth is -0.70 percent for states and -0.68 percent for MSAs. The 1 percentage point magnitude of the shock is relatively large given that the sample standard deviation (a statistical measure of a standard size of a shock) is 0.58 percentage points in states GVAR model and 0.48 percentage points in MSA GVAR model. The red dashed line shows the average cumulative impact on state employment (-0.69 percentage points) and MSA employment (-0.61 percentage points). 


\section{References}

Altonji, J. G. and J. C. Ham (1990). Variation in employment growth in Canada: The role of external, national, regional, and industrial factors. Journal of Labor Economics 8, S198-S236. https://doi.org/10.1086/298250.

Bailey, N., G. Kapetanios, and M. H. Pesaran (2016). Exponents of cross section dependence: Estimation and inference. Journal of Applied Econometrics 31, 929-1196. https://doi.org/10.1002/jae.2476.

Boschi, M. and A. Girardi (2011). The contribution of domestic, regional and international factors to Latin America's business cycle. Economic Modelling 28(3), 1235-1246. https://doi.org/10.1016/j.econmod.2011.01.002.

Campolieti, M., D. Gefang, and G. Koop (2014). A new look at variation in employment growth in Canada: The role of industry, provincial, national and external factors. Journal of Economic Dynamics and Control 41, 257-275. https://doi.org/10.1016/j.jedc.2014.02.005.

Carlino, G. A., R. H. DeFina, and K. Sill (2001). Sectoral shocks and metropolitan employment growth. Journal of Urban Economics 50, 396-417. https://doi.org/10.1006/juec.2001.2225.

Cesa-Bianchi, A., M. H. Pesaran, and A. Rebucci. (2018, February). Uncertainty and economic activity: A multi-country perspective. NBER working paper No. 24325. https://doi.org/10.3386/w24325.

Chang, S.-W. and N. E. Coulson (2001). Sources of sectoral employment fluctuations in central cities and suburbs: Evidence from four eastern U.S. cities. Journal of Urban Economics 49, 199-218. https://doi.org/10.1006/juec.2000.2192.

Chudik, A., V. Grossman, and M. H. Pesaran (2016). A multi-country approach to forecasting output growth using PMIs. Journal of Econometrics 192, 349-365. https://doi.org/10.1016/j.jeconom.2016.02.003.

Chudik, A., G. Kapetanios, and H. Pesaran (2018). A one covariate at a time, multiple testing approach to variable selection in high-dimensional linear regression models. Econometrica 86(4), 1479-1512. https://doi.org/10.3982/ecta14176. 
Chudik, A. and M. H. Pesaran (2011). Infinite dimensional VARs and factor models. Journal of Econometrics 163, 4-22. https://doi.org/10.1016/j.jeconom.2010.11.002.

Chudik, A. and M. H. Pesaran (2016). Theory and practice of GVAR modeling. Journal of Economic Surveys 30, 165-197. https://doi.org/10.1111/joes.12095.

Chudik, A., M. H. Pesaran, and E. Tosetti (2011). Weak and strong cross section dependence and estimation of large panels. Econometrics Journal 14, C45-C90. https://doi.org/10.1111/j.1368-423x.2010.00330.x.

Chudik, A. and R. Straub (2017). Size, openness, and macroeconomic interdependence. International Economic Review 58, 33-55. https://doi.org/10.1111/iere.12208.

Clark, T. and K. Shin (2000). The sources of fluctuations within and across countries. In G. D. Hess and E. Van Wincoop (Eds.), Intranational Macroeconomics, Chapter 9, pp. 189-217. Cambridge University Press. https://doi.org/10.2139/ssrn.140283.

Clark, T. E. (1998). Employment fluctuations in U.S. regions and industries: The role of national, regional and industry-specific shocks. Journal of Labor Economics 16, 202-229. https://doi.org/10.1086/209887.

Crucini, M. J., M. A. Kose, and C. Otrok (2011). What are the driving forces of international business cycles? Review of Economic Dynamics 14, 156-175. https://doi.org/10.1016/j.red.2010.09.001.

Dees, S., F. D. Mauro, M. H. Pesaran, and L. V. Smith (2007). Exploring the international linkages of the euro area: a Global VAR analysis. Journal of Applied Econometrics 22, 1-38. https://doi.org/10.1002/jae.932.

Del Negro, M. (2002). Asymmetric shocks among U.S. states. Journal of International Economics 56(2), 273-297. https://doi.org/10.1016/s0022-1996(01)00127-1.

Grossman, V., A. Mack, and E. Martínez-García (2013). A database of global economic indicators (DGEI): A methodological note. Globalization and Monetary Policy Institute Working Paper 166, Federal Reserve Bank of Dallas. chttps://doi.org/10.24149/gwp166.

Grossman, V., A. Mack, and E. Martínez-García (2014). A new database of global economic indicators. Journal of Economic and Social Measurement 39(3), 163-197. 
https://doi.org/10.3233/JEM-140391.

Guerron-Quintana, P. A. (2013). Common and idiosyncratic disturbances in developed small open economies. Journal of International Economics 90(1), 33-49. https://doi.org/10.1016/j.jinteco.2012.10.002.

Karadimitropoulou, A. and M. León-Ledesma (2013). World, country, and sector factors in international business cycles. Journal of economic dynamics and control 37(12), 2913-2927. https://doi.org/10.1016/j.jedc.2013.09.002.

Koech, J. and M. Wynne (2017). Diversification and specialization of U.S. states. The Review of Regional Studies 47(1), 63-91. Diversification and specialization of U.S. states.

Koop, G., M. H. Pesaran, and S. M. Potter (1996). Impulse response analysis in nonlinear multivariate models. Journal of Econometrics 74, 119-147. https://doi.org/10.1016/03044076(95)01753-4.

Kuttner, K. N. and A. Sbordone (1997). Sources of New York employment fluctuations. Federal Reserve Bank of New York Economic Policy Review, 21-35.

Norrbin, S. C. and D. E. Schlagenhauf (1988). An inquiry into the sources of macroeconomic fluctuations. Journal of Monetary Economics 22(1), 43-70. https://doi.org/10.1016/03043932(88)90169-9.

Norrbin, S. C. and D. E. Schlagenhauf (1996). The role of international factors in the business cycle: A multi-country study. Journal of International Economics 40(1-2), 85-104. https://doi.org/10.1016/0022-1996(95)01385-7.

Pesaran, M. H. (2004,). General diagnostic tests for cross section dependence in panels. CESifo Working Paper 1229, IZA Discussion Paper 1240.

Pesaran, M. H. (2015). Testing weak cross-sectional dependence in large panels. Econometric Reviews 34, 1089-1117. https://doi.org/10.1080/07474938.2014.956623.

Pesaran, M. H., T. Schuermann, and S. M. Weiner (2004). Modelling regional interdependencies using a global error-correcting macroeconometric model. Journal of Business and Economics Statistics 22, 129-162. https://doi.org/10.1198/073500104000000019. 
Pesaran, M. H. and Y. Shin (1998). Generalised impulse response analysis in linear multivariate models. Economics Letters 58, 17-29. https://doi.org/10.1016/s0165-1765(97)00214-0.

Pesaran, M. H. and R. P. Smith (2014). Signs of impact effects in time series regression models. Economics Letters 122, 150-153. https://doi.org/10.1016/j.econlet.2013.11.015.

Prasad, E. and A. Thomas (1998). A disaggregated analysis of employment growth fluctuations in Canada. Atlantic Economic Journal 26, 274-287. https://doi.org/10.1007/bf02299345.

Raddatz, C. (2007). Are external shocks responsible for the instability of output in low-income countries? Journal of Development Economics 84(1), 155-187. https://doi.org/10.1016/j.jdeveco.2006.11.001.

Wall, H. J. (2013). The employment cycles of neighboring cities. Regional Science and Urban Economics 43(1), 177-185. https://doi.org/10.1016/j.regsciurbeco.2012.06.008. 


\section{A Appendix}

This appendix is organized as follows. Section A.1 describes the data, Section A.2 provides details on variance decompositions, Section A.3 provides details on generalized impulse-response analysis, Section A.4 describes the bootstrapping procedures, and Section A.5 presents additional figures and tables.

\section{A.1 Data}

Table A1: Description of GVAR variables

\begin{tabular}{cccc}
\hline \hline \multicolumn{1}{c}{ Variable } & Geographic coverage & Time coverage & Sources \\
\hline \multirow{2}{*}{$\begin{array}{c}\text { U.S. employment } \\
\text { Employment by state } \\
\text { Employment by MSA }\end{array}$} & U.S. & 1980Q2:2016Q4 & BLS/Haver Analytics \\
\hline \multirow{2}{*}{$\begin{array}{c}\text { U.S. output } \\
\text { Foreign output }\end{array}$} & A15 U.S. MSAs & 1980Q2:2016Q4 & BLS/Haver Analytics \\
& Argentina, Australia, Austria, Belgium, & 1980Q2:2016Q4 & DGEI database by \\
& Canada, China, Colombia, France, Germany, & 1990Q2:2016Q4 & BLS/Haver Analytics \\
\hline & Italy, Japan, Korea, Mexico, Netherlands, & & Grossman et al. (2014)*** \\
& Peru, Portugal, South Africa, Spain, & & \\
& Sweden, Switzerland, U.K. & & \\
\hline \hline
\end{tabular}

Notes: $\left(^{*}\right)$ Employment is measured as first difference of logarithms of quarterly total nonfarm payroll employment data. (**) Output is measured as first difference of logarithms of quarterly real GDP data. (***) The underlying source of this dataset are national statistical offices as reported in Table 7 of Grossman et al. (2013). BLS stands for Bureau of Labor Statistics, and BEA stands for Bureau of Economic Analysis. 
Table A2: Description of State-level indicators

\begin{tabular}{|c|c|c|c|}
\hline Indicator & Measurement & $\begin{array}{c}\text { Time } \\
\text { period }\end{array}$ & $\begin{array}{c}\text { Data } \\
\text { Sources* }\end{array}$ \\
\hline Exports share of GSP & Percent share of exports in state gross state product (GSP) & $1996-2016$ & $\mathrm{CB} ; \mathrm{BEA} / \mathrm{HA}$ \\
\hline Imports share of GSP & Percent share of imports in state GSP & $2008-2016$ & $\mathrm{CB} ; \mathrm{BEA} / \mathrm{HA}$ \\
\hline Employment tied to exports & Jobs tied to state exports as a percent share of wage and salary employment & $2000-2015$ & ITA \\
\hline GSP share of US GDP & Percent share of state GSP in total U.S. GDP & $1980-2016$ & $\mathrm{BEA} / \mathrm{HA}$ \\
\hline Manufacturing share of GSP & Percent share of manufacturing GSP in total state GSP & $1997-2016$ & $\mathrm{BEA} / \mathrm{HA}$ \\
\hline Mining share of GSP & Percent share of mining GSP in total state GSP & $1997-2016$ & $\mathrm{BEA} / \mathrm{HA}$ \\
\hline Construction share of GSP & Percent share of construction GSP in total state GSP & $1997-2016$ & $\mathrm{BEA} / \mathrm{HA}$ \\
\hline Agriculture share of GSP & Percent share of agriculture GSP in total state GSP & $1997-2016$ & $\mathrm{BEA} / \mathrm{HA}$ \\
\hline Government share of GSP & Percent share of government GSP in total state GSP & $1997-2016$ & $\mathrm{BEA} / \mathrm{HA}$ \\
\hline FIRE share of GSP & Percent share of fire, insurance and real estate sector GSP in total state GSP & $1997-2016$ & $\mathrm{BEA} / \mathrm{HA}$ \\
\hline W \& $\mathrm{R}$ trade share of GSP & Percent share of wholesale and retail trade GSP in total state GSP & $1997-2016$ & $\mathrm{BEA} / \mathrm{HA}$ \\
\hline Services share of GSP & Percent share of services GSP in total state GSP & $1997-2016$ & $\mathrm{BEA} / \mathrm{HA}$ \\
\hline TPU share of GSP & Percent share of transportation and utilities sector's GSP in total state GSP & $1997-2016$ & $\mathrm{BEA} / \mathrm{HA}$ \\
\hline Herfindahl index (destination) & Index measuring diversification of state exports by export destinations & $1997-2014$ & $\mathrm{KW}$ \\
\hline Herfindahl index (product) & Index measuring diversification of state exports by export product & $1997-2014$ & KW \\
\hline Education (18-24) no highsch & Percent of population 18-24 with less than high school education in total pop aged 18-24 & $2005-2016$ & $\mathrm{CB} / \mathrm{HA}$ \\
\hline Education (18-24) college & Percent of population 18-24 with bachelor's degree or higher in total pop aged 18-24 & $2005-2016$ & $\mathrm{CB} / \mathrm{HA}$ \\
\hline Education $(25+)$ no highsch & Percent of population $25+$ with less than high school education in total pop aged $25+$ & $2005-2016$ & $\mathrm{CB} / \mathrm{HA}$ \\
\hline Education $(25+)$ college & Percent of population $25+$ with bachelor's degree or higher in total pop aged $25+$ & $2006-2016$ & $\mathrm{CB} / \mathrm{HA}$ \\
\hline Population growth & Averages of annual total population growth rates & $1980-2017$ & $\mathrm{CB} / \mathrm{HA}$ \\
\hline Real GSP per capita & Real GSP as a share of state population (in thousands) & $1980-2017$ & $\mathrm{BEA} / \mathrm{HA}$ \\
\hline Net migration** & Net domestic migration plus net international migration as a share of state population & $1991-2017$ & $\mathrm{BEA} / \mathrm{HA}$ \\
\hline Building permits** & Number of permits for new privately owned building as a share state construction output & $1980-2017$ & $\mathrm{BEA} / \mathrm{HA}$ \\
\hline Employment of foreign MNCs** & Employment of majority owned U.S. affiliates of foreign multinationals as a share of emp & $2007-2017$ & $\mathrm{BEA} / \mathrm{HA}$ \\
\hline Business bankruptcies** & Business bankruptcy filings in the state as a share of state GSP & $1980-2017$ & $\mathrm{BEA} / \mathrm{HA}$ \\
\hline NonBusiness bankruptcies** & Nonbusiness bankruptcy filings in the state as a share of state GSP & $1980-2017$ & $\mathrm{BEA} / \mathrm{HA}$ \\
\hline Government debt share of GSP & Outstanding state government debt as a percent share of state GSP & 1993-2015 & $\mathrm{CB} ; \mathrm{BEA} / \mathrm{HA}$ \\
\hline Average temperature & Average temperature in a state relative to the U.S. national average (state temp-U.S. temp) & $1980-2015$ & $\mathrm{NCDC} / \mathrm{HA}$ \\
\hline Average precipitation & Average precipitation in a state relative to the U.S. national average (state temp-U.S. temp) & $1980-2015$ & $\mathrm{NCDC} / \mathrm{HA}$ \\
\hline Heating degree days & Heating Degree Days index measures heating energy requirements (state HDD-U.S.HDD) & $1997-2017$ & $\mathrm{NCDC} / \mathrm{HA}$ \\
\hline Cooling degree days & Cooling Degree Days index measures cooling energy requirements (state CDD-U.S.CDD) & $1999-2017$ & $\mathrm{NCDC} / \mathrm{HA}$ \\
\hline Auto debt per capita & Outstanding auto debt balance per capita in the state & $1999-2017$ & FRBNY / HA \\
\hline Credit card debt per capita & Outstanding credit card debt balance per capita in the state & $1999-2017$ & FRBNY/HA \\
\hline Mortgage debt per capita & Outstanding mortgage debt balance per capita in the state & $1999-2017$ & FRBNY / HA \\
\hline Homeownership rate & Owner-occupied housing units as share of total occupied housing unit & $1984-2017$ & $\mathrm{CB} / \mathrm{HA}$ \\
\hline Median home values & Zillow estimates of median home values measured by the Zillow Home Value Index & $1997-2017$ & Zillow / H A \\
\hline Motor vehicle registrations & Number of motor vehicle registrations as a share of state population & $1980-2017$ & $\mathrm{FHA} / \mathrm{HA}$ \\
\hline Motor vehicle miles per capita & Number of annual motor vehicle miles traveled as a share of state population & $1989-2017$ & $\mathrm{FHA} / \mathrm{HA}$ \\
\hline Rate of natural increase & Rate of natural increase is computed as births minus deaths as a share of state population & $2001-2017$ & $\mathrm{CB} / \mathrm{HA}$ \\
\hline Poverty rates & Number of people below poverty level as a percent share of total state population & $1980-2016$ & $\mathrm{CB} / \mathrm{HA}$ \\
\hline Population density & Number of people per square mile & $1980-2017$ & $\mathrm{CB} / \mathrm{HA}$ \\
\hline Prisoners per capita & Prisoners under state and federal correctional authorities as a share of state population & $1982-2016$ & B JS / H A \\
\hline Per capita personal income & Real personal income in chained 2009 dollars as a share of state population & $1980-2017$ & $\mathrm{BEA} / \mathrm{HA}$ \\
\hline State tax rates & State and local taxes collected as a percent share of total state income taxes & $1980-2012$ & $\mathrm{TF}$ \\
\hline Taxes per capita & State and local taxes collected as a share of state population & $1980-2012$ & $\mathrm{TF}$ \\
\hline Economic freedom index & Index measures degree of economic freedom in govt., legal system, trade, and regulation & $1981-2015$ & FI \\
\hline Interstate imports share of GSI & Flow of goods into a state from all other U.S. states as a share of state GSP & 2012 & CFS \\
\hline Interstate exports share of GSP & Flow of goods out of a state to all other U.S. states as a share of state GSP & 2012 & CFS \\
\hline
\end{tabular}

Notes: All shares are expressed in percent. Geographic coverage for all variables is for each of the 50 U.S. states plus Washington D.C., (*) CB = Census Bureau, BEA = Bureau of Economic Analysis, HA = Haver Analytics, KW=Koech and Wynne (2017), ITA = International Trade Administration. NCDC = National Climatic Data Center; FRBNY = Federal Reserve Bank of New York; BJS = Bureau of Justice Statistics; CFS = Commodity Flow Survey; FHA = Federal Highway Administration; TF $=$ Tax Foundation; FI = Fraser Institute (**) These variables are scaled by 1,000,000 to adjust for their small values. 
Table A3: Description of MSA-level indicators

\begin{tabular}{|c|c|c|c|}
\hline Variable & Measurement & $\begin{array}{c}\text { Time } \\
\text { coverage }\end{array}$ & $\begin{array}{c}\text { Data } \\
\text { Sources* }\end{array}$ \\
\hline Exports share of GDP & Percent share of exports in MSA gross domestic product (GDP) & $1996-2016$ & $\mathrm{CB} ; \mathrm{BEA} / \mathrm{HA}$ \\
\hline Real GDP growth & Annual average growth rate of real GDP in each MSA & $2008-2016$ & $\mathrm{CB} ; \mathrm{BEA} / \mathrm{HA}$ \\
\hline GSP share of US GDP & Percent share of MSA GDP in total U.S. GDP & $1980-2016$ & $\mathrm{BEA} / \mathrm{HA}$ \\
\hline Education (18-24) no highsch & Percent of population 18-24 with less than high school education in total pop aged 18-24 & $2005-2016$ & $\mathrm{CB} / \mathrm{HA}$ \\
\hline Education (18-24) college & Percent of population 18-24 with bachelor's degree or higher in total pop aged 18-24 & $2005-2016$ & $\mathrm{CB} / \mathrm{HA}$ \\
\hline Education $(25+)$ no highsch & Percent of population $25+$ with less than high school education in total pop aged $25+$ & $2005-2016$ & $\mathrm{CB} / \mathrm{HA}$ \\
\hline Education $(25+)$ college & Percent of population $25+$ with bachelor's degree or higher in total pop aged $25+$ & 2006-2016 & $\mathrm{CB} / \mathrm{HA}$ \\
\hline Population growth & Averages of annual total population growth rates & $1980-2017$ & $\mathrm{CB} / \mathrm{HA}$ \\
\hline Real GSP per capita & Real GDP as a share of MSA population (in thousands) & $1980-2017$ & $\mathrm{BEA} / \mathrm{HA}$ \\
\hline Net migration** & Net domestic migration plus net international migration as a share of MSA population & 1991-2017 & $\mathrm{BEA} / \mathrm{HA}$ \\
\hline Building permits** & Number of permits for new privately owned building as a share MSA GDP & $1980-2017$ & $\mathrm{BEA} / \mathrm{HA}$ \\
\hline Business bankruptcies** & Business bankruptcy filings in the MSA as a share of MSA GSP & $1980-2017$ & $\mathrm{BEA} / \mathrm{HA}$ \\
\hline NonBusiness bankruptcies** & Nonbusiness bankruptcy filings in the MSA as a share of MSA GSP & $1980-2017$ & $\mathrm{BEA} / \mathrm{HA}$ \\
\hline Median home values & Zillow estimates of median home values in a region measured by the Zillow Home Value Index & $1997-2017$ & Zillow / HA \\
\hline Poverty rates & Number of people below poverty level as a percent share of total MSA population & $1980-2016$ & $\mathrm{CB} / \mathrm{HA}$ \\
\hline Per capita personal income & Real personal income in chained 2009 dollars as a share of MSA population & $1980-2017$ & $\mathrm{BEA} / \mathrm{HA}$ \\
\hline
\end{tabular}

Notes: $(*) \mathrm{CB}=$ Census Bureau, BEA = Bureau of Economic Analysis, $\mathrm{HA}=$ Haver Analytics, AOC $=$

Administrative Office of the U.S. Courts. $\left(^{* *}\right)$ These variables are scaled by $1,000,000$ to adjust for their small values.

\section{A.2 Variance Decompositions}

Stacking (5) and (6), yields the following GVAR representation of the vector of all variables $\boldsymbol{\xi}_{t}=$ $\left(\mathbf{z}_{t}^{\prime}, \mathbf{h}_{t}^{\prime}\right)^{\prime}$

$$
\boldsymbol{\xi}_{t}=\mathbf{c}_{\xi}+\sum_{\ell=1}^{p} \mathbf{G}_{\boldsymbol{\xi}, \ell} \boldsymbol{\xi}_{t-\ell}+\gamma v_{t}+\mathbf{B} \boldsymbol{\eta}_{t}
$$

where $\mathbf{c}_{\xi}=\left(\mathbf{c}_{z}^{\prime}, \mathbf{c}_{h}^{\prime}\right)^{\prime}, \gamma=\left(\mathbf{a}_{0}^{\prime}, \boldsymbol{\delta}^{\prime}\right)^{\prime}, \boldsymbol{\eta}_{t}=\left(\mathbf{e}_{t}^{\prime}, \varepsilon_{t}^{\prime}\right)^{\prime}$

$$
\mathbf{G}_{\boldsymbol{\xi}, \ell}=\left(\begin{array}{cc}
\mathbf{G}_{z, \ell} & \mathbf{0} \\
\mathbf{G}_{h z, \ell} & \mathbf{\Psi}_{\ell}
\end{array}\right), \text { for } \ell=1,2, \ldots, p, \text { and } \mathbf{B}=\left(\begin{array}{cc}
\mathbf{I} & \mathbf{0} \\
\boldsymbol{\Lambda}_{0} \mathbf{S}_{N} & \mathbf{I}
\end{array}\right)
$$

It is useful to define $\mathbf{G}_{\boldsymbol{\xi}}(L)=\mathbf{I}-\sum_{\ell=1}^{p} \mathbf{G}_{\boldsymbol{\xi}, \ell} L^{\ell}$, and its inverse, $\mathbf{Q}_{\boldsymbol{\xi}}(L)=\mathbf{G}_{\boldsymbol{\xi}}^{-1}(L)=\sum_{\ell=0}^{\infty} \mathbf{Q}_{\boldsymbol{\xi}, \ell} L^{\ell} .9$ In addition, let $\mathbf{S}_{h}$ be the selection matrix that selects sub-vector $\mathbf{h}_{t}$ of $\boldsymbol{\xi}_{t}=\left(\mathbf{z}_{t}^{\prime}, \mathbf{h}_{t}^{\prime}\right)^{\prime}$, namely

\footnotetext{
${ }^{9}$ We note that $\mathbf{Q}_{\boldsymbol{\xi}, 0}=\mathbf{I}$.
} 
$\mathbf{h}_{t}=\mathbf{S}_{h} \boldsymbol{\xi}_{t}$. Then the total variance of regional employment variables is given by

$$
V_{h}^{t o t}=\mathbf{S}_{h} \sum_{\ell=0}^{\infty} \mathbf{Q}_{\xi, \ell} \boldsymbol{\Sigma}_{\xi}^{t o t} \mathbf{Q}_{\xi, \ell} \mathbf{S}_{h}^{\prime}, \text { where } \boldsymbol{\Sigma}_{\xi}^{t o t}=\gamma \gamma^{\prime} \sigma_{v}^{2}+\mathbf{B} \boldsymbol{\Sigma}_{\eta} \mathbf{B}^{\prime}
$$

in which $\sigma_{v}^{2}=\operatorname{Var}\left(v_{t}\right)$ and $\boldsymbol{\Sigma}_{\eta}=\operatorname{Var}\left(\boldsymbol{\eta}_{t}\right)$. In the estimation of $\boldsymbol{\Sigma}_{\eta}$, we impose $\operatorname{cov}\left(\mathbf{e}_{N t}, \boldsymbol{\varepsilon}_{t}\right)=\mathbf{0}$ which follows from he specifications of our models, but the remaining elements of $\boldsymbol{\Sigma}_{\eta}$ are unrestricted. The variance of regional employment variables explained by the global shock $v_{t}$ alone is

$$
V_{h}^{g l o b}=\mathbf{S}_{h} \sum_{\ell=0}^{\infty} \mathbf{Q}_{\xi, \ell} \boldsymbol{\Sigma}_{\xi}^{g l o b} \mathbf{Q}_{\xi, \ell} \mathbf{S}_{h}^{\prime}, \text { where } \boldsymbol{\Sigma}_{\xi}^{g l o b}=\gamma \gamma^{\prime} \sigma_{v}^{2}
$$

Similarly, the variance of $\mathbf{h}_{t}$ explained by the U.S. national shocks is given by

$$
V_{h}^{g l o b}=\mathbf{S}_{h} \sum_{\ell=0}^{\infty} \mathbf{Q}_{\xi, \ell} \boldsymbol{\Sigma}_{\xi}^{n a t} \mathbf{Q}_{\xi, \ell} \mathbf{S}_{h}^{\prime}, \text { where } \boldsymbol{\Sigma}_{\xi}^{n a t}=\mathbf{B S}_{\mathbf{N}} E\left(\mathbf{e}_{N t} \mathbf{e}_{N t}^{\prime}\right) \mathbf{S}_{\mathbf{N}}^{\prime} \mathbf{B}^{\prime}
$$

\section{A.3 Generalized Impulse Response Functions}

Generalized IRFs are obtained from the GVAR representation (A.1) in a standard fashion. In particular, the vector of GIRFs for a one s.e. increase in $v_{t}$ on U.S. regional employment variables is given by

$$
\begin{aligned}
\operatorname{GIRF}_{v}(\ell) & =E\left(\mathbf{h}_{t+\ell} \mid v_{t}=1, \mathcal{I}_{t-1}\right)-E\left(\mathbf{h}_{t+\ell} \mid \mathcal{I}_{t-1}\right) \\
& =\mathbf{S}_{h} \mathbf{Q}_{\xi, \ell} \gamma \sigma_{v},
\end{aligned}
$$

where $\mathbf{S}_{h}, \mathbf{Q}_{\xi, \ell}$ and $\gamma$ are defined in Section A.2, and $\mathcal{I}_{t}$ is the information set consisting of all information up to time period $t$. Denote the two row vectors of $\mathbf{S}_{N}$ as $\mathbf{S}_{N}=\left(\mathbf{s}_{N, y}^{\prime}, \boldsymbol{s}_{N, h}^{\prime}\right)$ so that $y_{N t}=\mathbf{s}_{N, y}^{\prime} \mathbf{z}_{t}$ and $h_{N t}=\mathbf{s}_{N, h}^{\prime} \mathbf{z}_{t}$. In addition, partition the U.S. national shocks $\mathbf{e}_{N t}$ as $\mathbf{e}_{N t}=\left(e_{N y t}, e_{N h t}\right)^{\prime}$. Then, the GIRF of one s.e. increase in $e_{N y t}$ is given by

$$
\begin{aligned}
\operatorname{GIRF}_{e_{N y}}(\ell) & =E\left(\mathbf{h}_{t+\ell} \mid e_{N y t}=1, \mathcal{I}_{t-1}\right)-E\left(\mathbf{h}_{t+\ell} \mid \mathcal{I}_{t-1}\right) \\
& =\frac{\mathbf{S}_{h} \mathbf{Q}_{\xi, \ell} \boldsymbol{\Sigma}_{\xi}^{n a t} \mathbf{s}_{N, y}}{\sqrt{\mathbf{s}_{N, y}^{\prime} \boldsymbol{\Sigma}_{\xi}^{n a t} \mathbf{s}_{N, y}}}
\end{aligned}
$$


Similarly, the GIRF for a one s.e. increase in $e_{N h t}$ is given by

$$
\begin{aligned}
\operatorname{GIRF}_{e_{N h}}(\ell) & =E\left(\mathbf{h}_{t+\ell} \mid e_{N h t}=1, \mathcal{I}_{t-1}\right)-E\left(\mathbf{h}_{t+\ell} \mid \mathcal{I}_{t-1}\right) \\
& =\frac{\mathbf{S}_{h} \mathbf{Q}_{\xi, \ell} \boldsymbol{\Sigma}_{\xi}^{n a t} \mathbf{s}_{N, h}}{\sqrt{\mathbf{s}_{N, y}^{\prime} \boldsymbol{\Sigma}_{\xi}^{n a t} \mathbf{s}_{N, h}}}
\end{aligned}
$$

\section{A.4 Bootstrapping Procedures}

The estimated GVAR model (A.1) is given by $\boldsymbol{\xi}_{t}=\hat{\mathbf{c}}_{\xi}+\sum_{\ell=1}^{p} \hat{\mathbf{G}}_{\boldsymbol{\xi}, \ell} \mathbf{z}_{t-\ell}+\hat{\gamma} \hat{v}_{t}+\hat{\mathbf{B}} \hat{\boldsymbol{\eta}}_{t}$, where we used hats to denote the sample LS estimates. Using these estimates, we generate $R$ bootstrap samples denoted by $\boldsymbol{\xi}_{t}^{(r)}$, for $r=1,2, \ldots, R$, computed as

$$
\boldsymbol{\xi}_{t}^{(r)}=\hat{\mathbf{c}}_{\xi}+\sum_{\ell=1}^{p} \hat{\mathbf{G}}_{\boldsymbol{\xi}, \ell} \boldsymbol{\xi}_{t-\ell}^{(r)}+\hat{\gamma} v_{t}^{(r)}+\hat{\mathbf{B}} \hat{\boldsymbol{\eta}}_{t}^{(r)}, \text { for } t=1,2, \ldots, T
$$

with initial values set to the actual data vectors, $\boldsymbol{\xi}_{-\ell}^{(r)}=\boldsymbol{\xi}_{-\ell}$ for $\ell=0,1, \ldots, p-1$, and by resampling with replacement the columns of the matrix of residuals

$$
\hat{\Omega}=\left(\begin{array}{cccc}
\hat{\boldsymbol{\eta}}_{1} & \hat{\boldsymbol{\eta}}_{2} & \cdots & \hat{\boldsymbol{\eta}}_{T}
\end{array}\right)=\left(\begin{array}{cccc}
\hat{\mathbf{e}}_{1}^{\prime} & \hat{\mathbf{e}}_{2}^{\prime} & \cdots & \hat{\mathbf{e}}_{T}^{\prime} \\
\hat{\boldsymbol{\varepsilon}}_{1} & \hat{\boldsymbol{\varepsilon}}_{2} & \cdots & \hat{\boldsymbol{\varepsilon}}_{T}
\end{array}\right)^{\prime} .
$$

Generated bootstrap samples $\boldsymbol{\xi}_{t}^{(r)}$ are used to estimate the GVAR model, and the objects of interests (impulse-responses and variance decompositions). $(1-\alpha) \%$ confidence sets are given by the $\alpha / 2$ and $1-\alpha / 2$ quantiles. The number of bootstrap replication is set to $R=2000$.

The cross-section regression (8) is bootstrapped as follows. We generate $R$ bootstrap samples $\tilde{u}_{\ell}^{(r)}=\varkappa_{\ell}^{(r)} \hat{u}_{\ell}$, for $\ell=1,2, \ldots, n$, where $\varkappa_{\ell}^{(r)}$ are i.i.d. and generated such that

$$
\varkappa_{\ell}=\left\{\begin{array}{cc}
-1 & \text { with probability } 1 / 2 \\
1 & \text { with probability } 1 / 2
\end{array} .\right.
$$

Then, we generate $\boldsymbol{\zeta}^{(r)}=\mathbf{X} \hat{\boldsymbol{\beta}}+\tilde{\mathbf{u}}^{(r)}$, and compute the corresponding estimate

$$
\hat{\boldsymbol{\beta}}^{(r)}=\left(\mathbf{X}^{\prime} \mathbf{X}\right)^{-1} \mathbf{X}^{\prime} \boldsymbol{\zeta}^{(r)}
$$


and compute quantiles of $\left\{\hat{\boldsymbol{\beta}}^{(r)}, r=1,2, \ldots, R\right\}$. As before, we set $R=2000$.

\section{A.5 Additional Figures and Tables}

This section contains additional results that are intended for the working paper/online version of the paper but not necessarily for publication.

Panel A of Figure A1 shows employment growth for all fifty U.S. states plus the District of Columbia, while panel B shows employment growth for 255 of the metro areas in our sample. The figure shows that there is significant co-movement in employment at both the state and metro area level.

Panels A and B of Figure A2 provide confidence intervals for our estimates of the share of employment variation at the state and metro area level explained by global shocks. Note that the estimates for D.C., Louisiana, North Dakota and Alaska are not significantly different from zero.

Panels A and B of Figure A3 provide confidence intervals for our estimates of the share of employment variation at the state and metro area level explained by national shocks. Note that the estimates for D.C. and Wyoming are not significantly different from zero.

Panels A and B of Figure A4 provide confidence intervals for our estimates of the share of employment variation at the state and metro area level explained by residual (state- or metrospecific) shocks.

Table A4 repeats the exercise in Table 2, except that we look at the factors that help explain heterogeneity across states in the four-quarter cumulative impact of a global shock on state employment. Note that net migration explains more than a third of the variation across states in the four-quarter response to a global output shock, and is also selected by the OCMT procedure, along with several other indicators that do not show up in Table 2. However, once again the international trade measures do not make the cut.

Table A5 repeats the exercise in Table 2, except that we look at the factors that help explain heterogeneity across states in the four-quarter cumulative impact of a U.S. national output shock on state employment. Employment of foreign multinationals has the highest $R^{2}$ in the first stage regression, but it is not that different from the $R^{2}$ for population growth. The OCMT procedure picks just these two variables to explain cross-state variation in the four-quarter response of 
employment to a U.S. national output shock.

Table A6 repeats the exercise in Table 2, except that we look at the factors that help explain heterogeneity across states in the four-quarter cumulative impact of a U.S. national employment shock on state employment. Net migration rates and population growth both show up as important, as do the size of government relative to GSP, the share of agriculture in GSP and building permits.

Table A7 repeats the exercise in Table 3, except that we look at the factors that help explain heterogeneity across metro areas in the four-quarter cumulative impact of a global output shock on metro area employment. Note that our two measures of international linkages at the metro area level (exports as a share of GDP and net migration) both show up as statistically significant.

Table A8 repeats the exercise in Table 3, except that we look at the factors that help explain heterogeneity across metro areas in the four-quarter cumulative impact of a U.S. national output shock on metro area employment. Exports as a share of metro area GDP no longer show up as statistically significant, but net migration does, along with several other variables.

Table A9 repeats the exercise in Table 3, except that we look at the factors that help explain heterogeneity across metro areas in the four-quarter cumulative impact of a U.S. national employment shock on metro area employment. Exports and migration are again both significant. 
Figure A1: Yearly employment growth range across the U.S. states (A) and U.S. metropolitan areas (B)

A. U.S. states

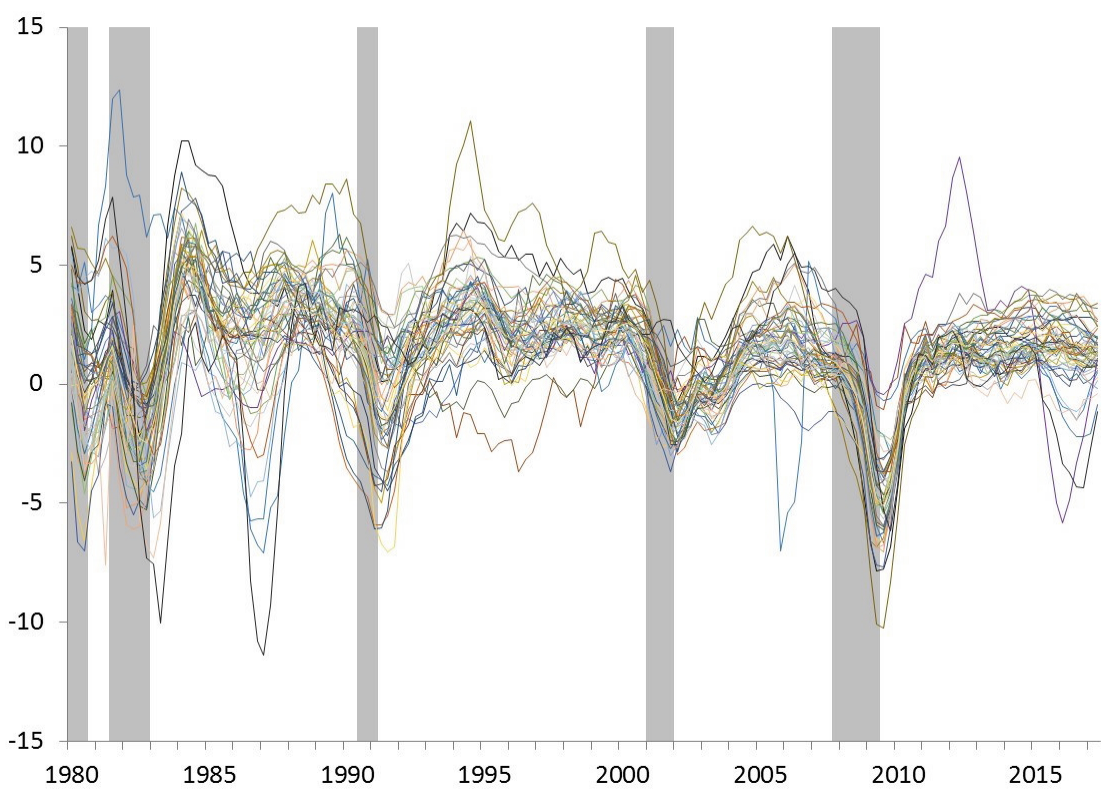

B. U.S. metropolitan areas

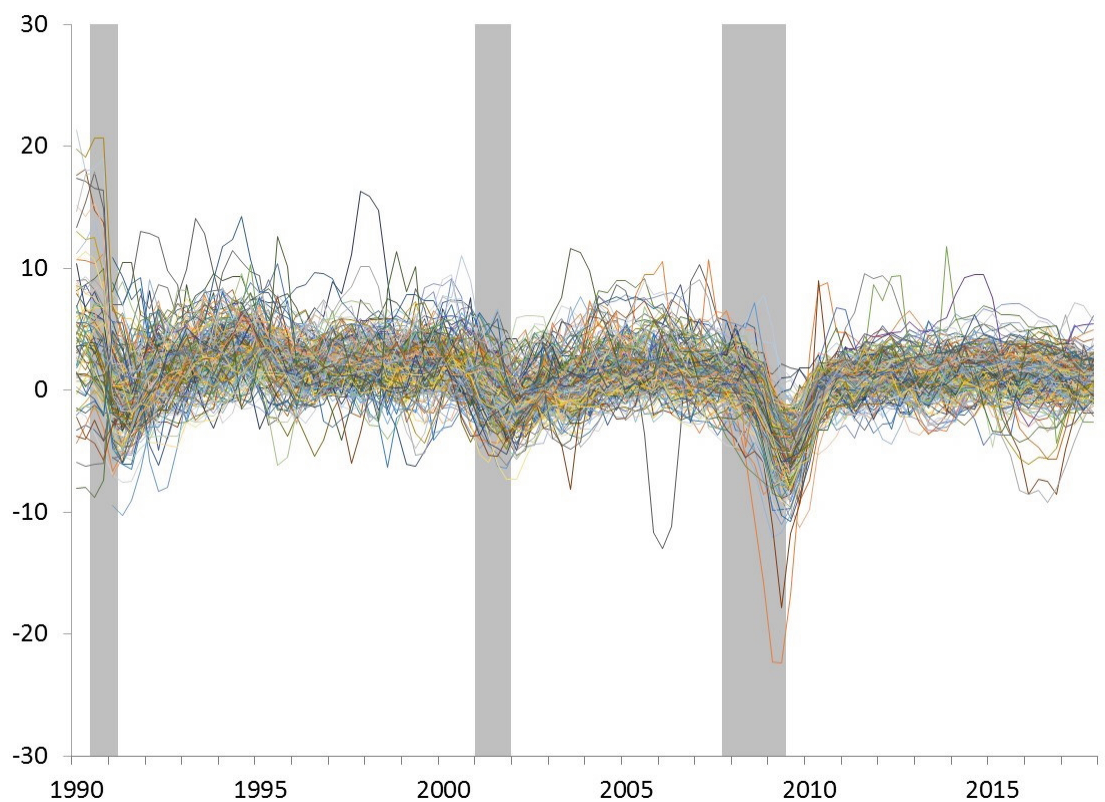

Notes: Employment fluctuations are computed as year-over-year growth of quarterly nonfarm payroll employment. Data for all 50 U.S. states plus DC are plotted in the top graph and for a sample of first 255 metro areas (in alphabetical order) in the bottom chart (A sample of 255 MSAs is used because of our graphics editor limitations) 
Figure A2: Share of U.S. states' employment variation explained by global shocks A. U.S. states

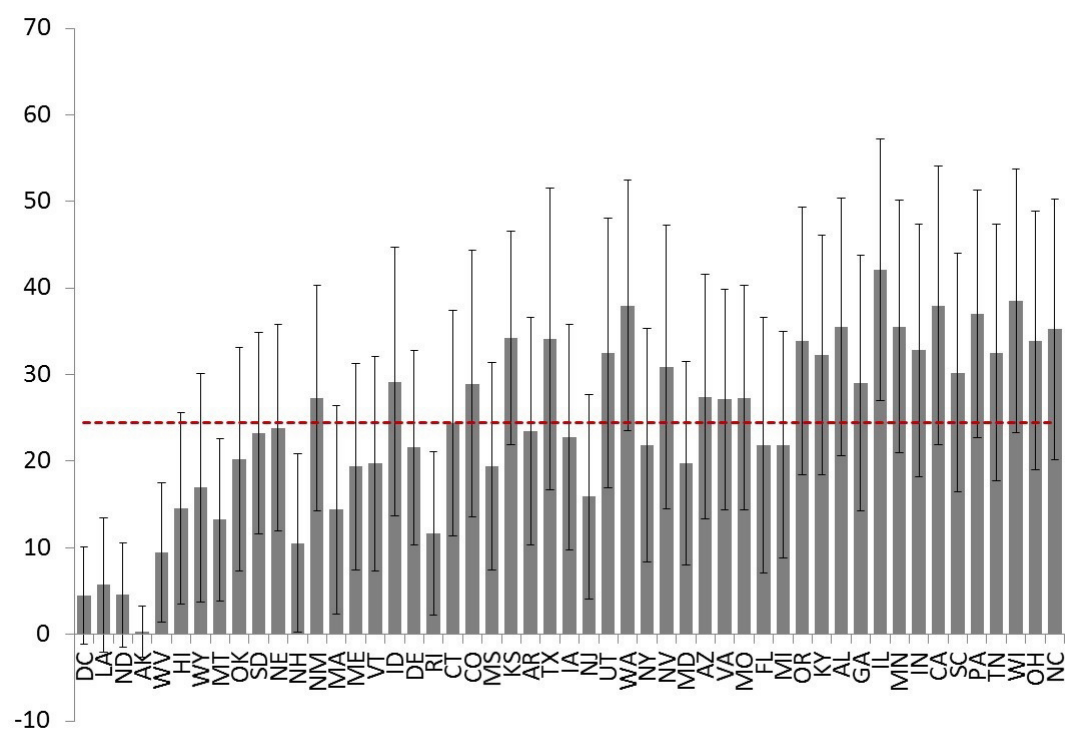

B. U.S. metropolitan areas

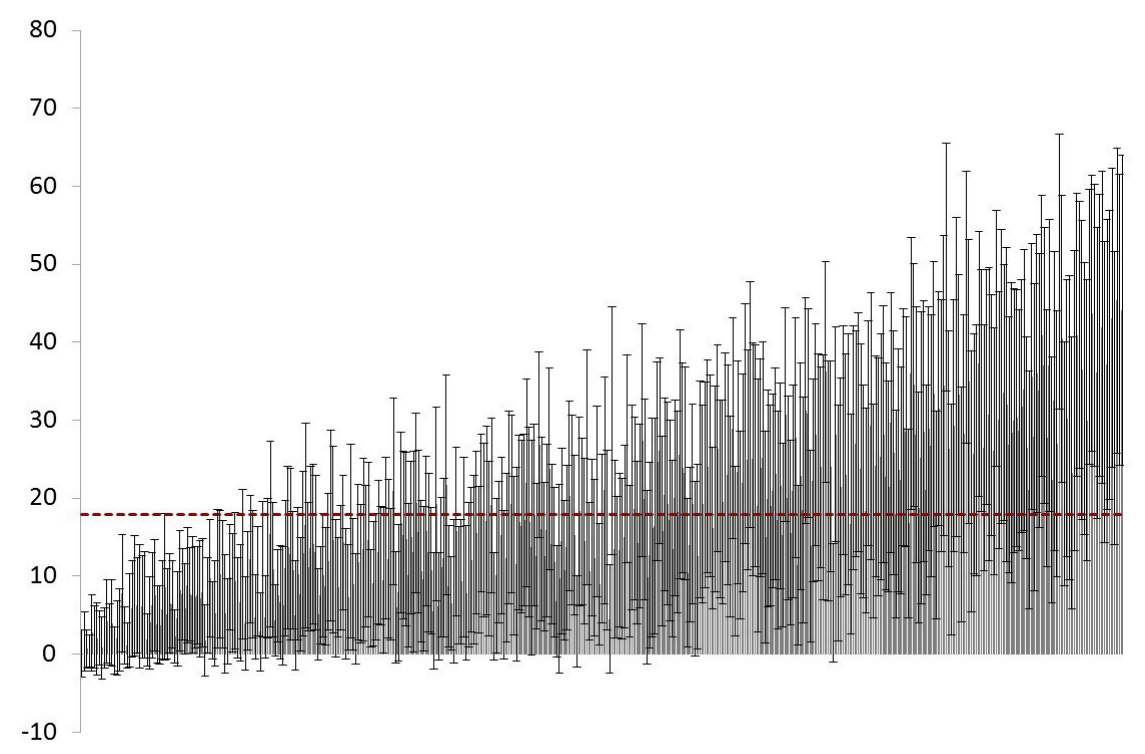

Notes: This figure shows the decomposition of the total variance of regional employment fluctuations to contributions from global shocks and 10\%-90\% confidence bounds, based on the GVAR model outlined in Section 3.2 . 
Figure A3: Share of U.S. states' employment variation explained by national shocks

A. U.S. states

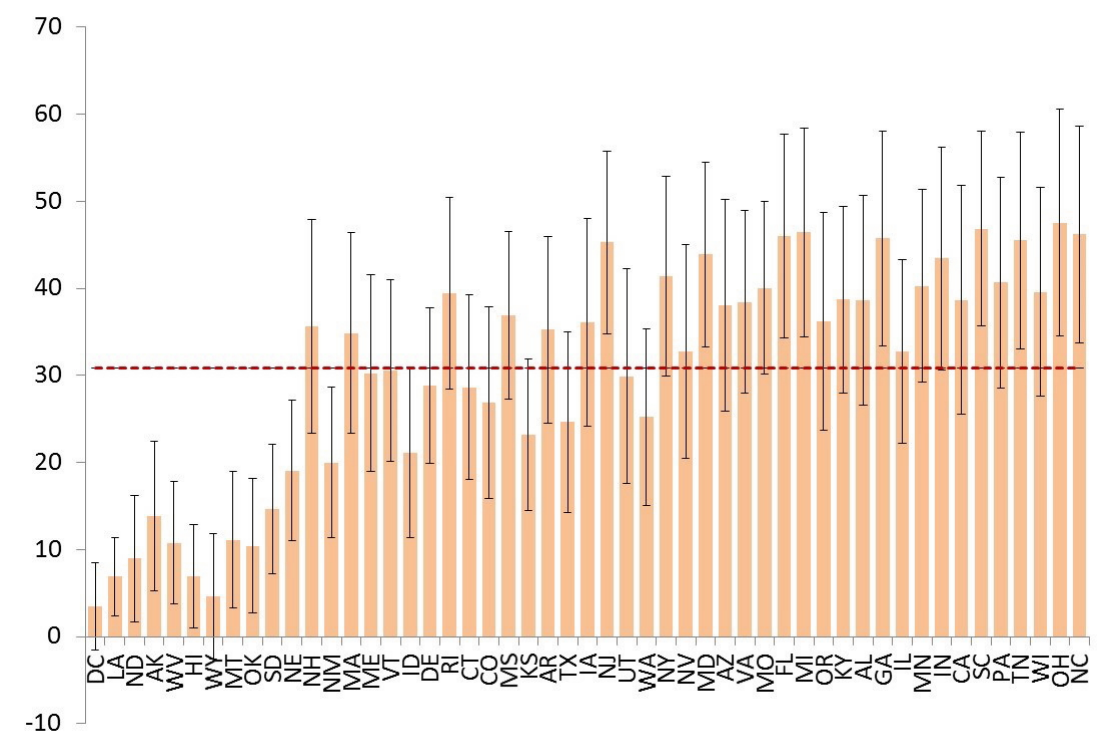

B. U.S. metropolitan areas

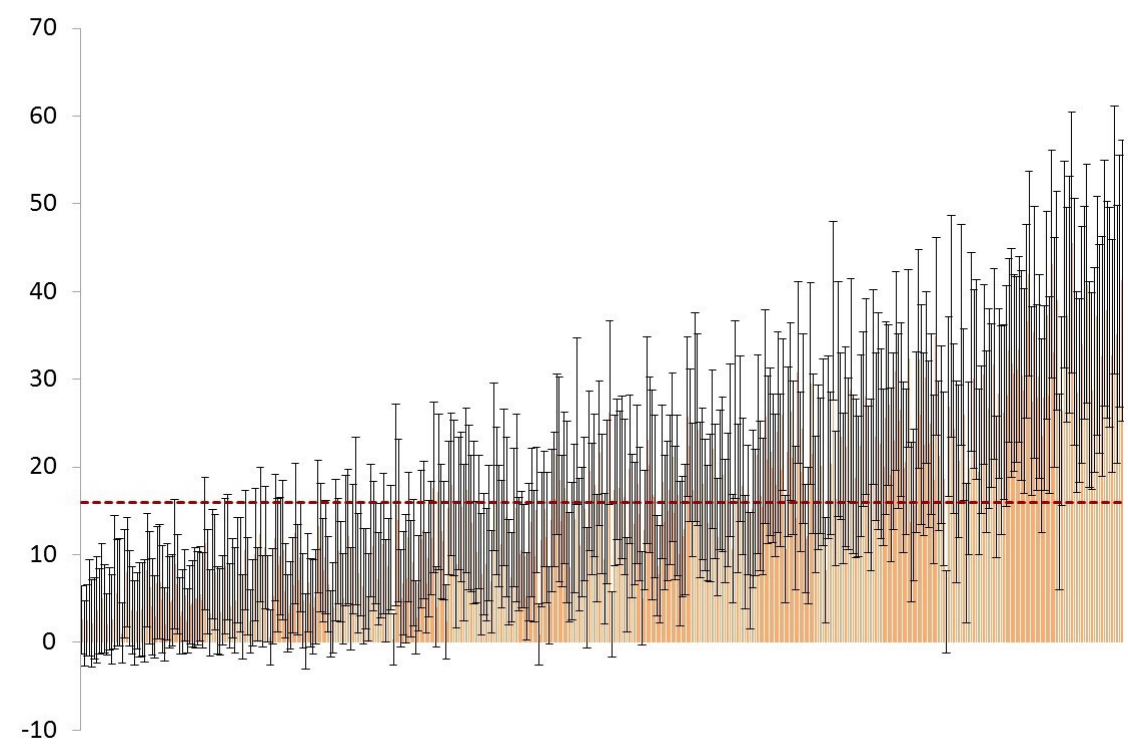

Notes: This figure shows the decomposition of the total variance of regional employment fluctuations to contributions from national shocks and 10\%-90\% confidence bounds, based on the GVAR model outlined in Section 3.2 . 
Figure A4: Share of U.S. states' employment variation explained by residual shocks

A. U.S. states

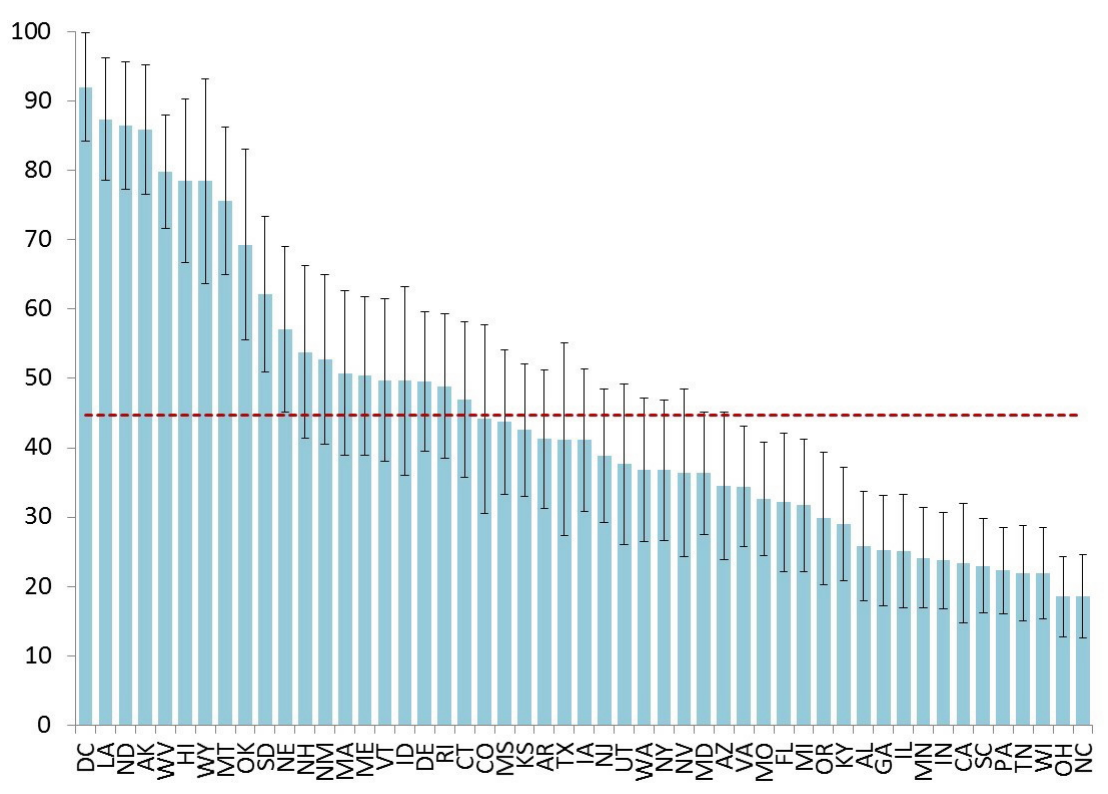

B. U.S. metropolitan areas

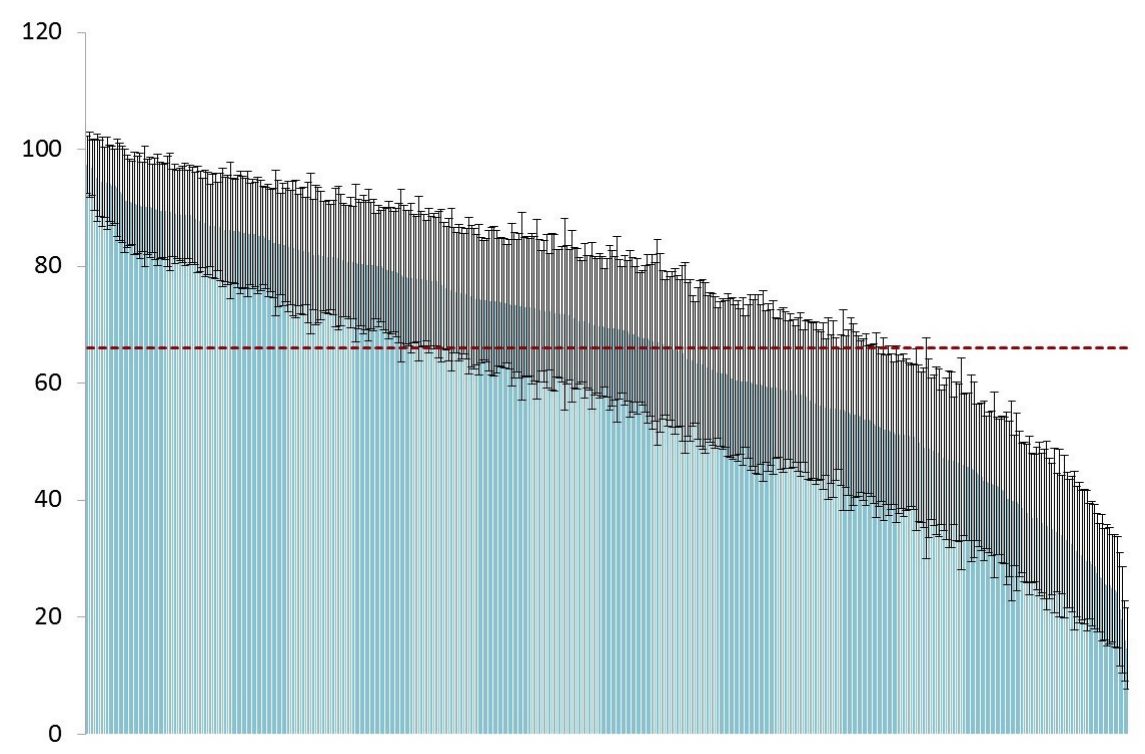

Notes: This figure shows the decomposition of the total variance of regional employment fluctuations to contributions from residual shocks and 10\%-90\% confidence bounds, based on the GVAR model outlined in Section 3.2 . 
Table A4: Explaining state heterogeneity in the four-quarter cumulative impacts of global output shock on state employment

\begin{tabular}{|c|c|c|c|c|}
\hline \multicolumn{5}{|c|}{ "Net effect coefficient estimates } \\
\hline (Regressors ordered based on $R^{2}$ ) & $\hat{\theta}$ & Conf. int. & $R^{2}$ & $n$ \\
\hline Net migration & 0.162 & {$[0.116,0.208]$} & 0.390 & 51 \\
\hline Building permits & 0.869 & {$[0.513,1.222]$} & 0.274 & 51 \\
\hline NonBusiness bankruptcies & 0.014 & {$[0.008,0.021]$} & 0.253 & 51 \\
\hline Construction share of GSP & 0.626 & {$[0.333,0.908]$} & 0.177 & 51 \\
\hline Population growth & 0.790 & {$[0.373,1.214]$} & 0.171 & 51 \\
\hline Per capita personal income & -0.109 & {$[-0.161,-0.057]$} & 0.168 & 51 \\
\hline Education (18-24) college & -0.163 & {$[-0.247,-0.079]$} & 0.158 & 51 \\
\hline Real GSP per capita & 0.000 & {$[0.000,0.000]$} & 0.153 & 51 \\
\hline Business bankruptcies & 0.139 & {$[0.062,0.216]$} & 0.152 & 51 \\
\hline MVehicle miles traveled per capita & 0.300 & {$[0.119,0.487]$} & 0.141 & 51 \\
\hline Education $(25+)$ college & -0.086 & {$[-0.123,-0.050]$} & 0.129 & 51 \\
\hline Average precipitation & -0.360 & {$[-0.638,-0.073]$} & 0.124 & 48 \\
\hline Manufacturing share of GSP & 0.083 & {$[0.014,0.151]$} & 0.121 & 51 \\
\hline Education (18-24) no highsch & 0.160 & {$[0.053,0.266]$} & 0.116 & 51 \\
\hline Credit card debt per capita & -1.006 & {$[-1.910,-0.081]$} & 0.101 & 51 \\
\hline Govt. share of GSP & -0.096 & {$[-0.152,-0.040]$} & 0.089 & 51 \\
\hline Population density & 0.000 & {$[0.000,0.000]$} & 0.086 & 51 \\
\hline W\&R trade share of GSP & 0.183 & {$[0.007,0.359]$} & 0.085 & 51 \\
\hline Heating degree days & 0.000 & {$[0.000,0.000]$} & 0.084 & 51 \\
\hline Interstate imports share of GSP & 0.021 & {$[0.000,0.041]$} & 0.066 & 51 \\
\hline Homeownership rate & 0.056 & {$[0.007,0.102]$} & 0.059 & 51 \\
\hline Median home values & -0.005 & {$[-0.009,0.000]$} & 0.056 & 51 \\
\hline Taxes per capita & -0.372 & {$[-0.734,-0.011]$} & 0.053 & 51 \\
\hline Government debt share of GSP & -0.087 & {$[-0.215,0.044]$} & 0.047 & 51 \\
\hline Interstate exports share of GSP & 0.014 & {$[-0.003,0.031]$} & 0.045 & 51 \\
\hline TPU share of GSP & -0.158 & {$[-0.517,0.201]$} & 0.035 & 51 \\
\hline Economic freedom index & 0.391 & {$[-0.234,1.039]$} & 0.033 & 50 \\
\hline Mining share of GSP & -0.041 & {$[-0.169,0.086]$} & 0.027 & 51 \\
\hline Herfindahl index (product) & 0.002 & {$[-0.002,0.005]$} & 0.024 & 50 \\
\hline Employment tied to exports & -0.106 & {$[-0.375,0.165]$} & 0.023 & 50 \\
\hline Education $(25+)$ no highsch & 0.119 & {$[-0.060,0.296]$} & 0.020 & 51 \\
\hline Auto debt per capita & 0.418 & {$[-0.403,1.211]$} & 0.019 & 51 \\
\hline Exports share of GSP & 0.048 & {$[-0.042,0.136]$} & 0.015 & 51 \\
\hline Herfindahl index (destination) & -0.002 & {$[-0.007,0.002]$} & 0.014 & 50 \\
\hline Cooling degree days & 0.000 & {$[0.000,0.001]$} & 0.013 & 51 \\
\hline MVehicle registrations & 0.001 & {$[-0.002,0.004]$} & 0.011 & 51 \\
\hline Services share of GSP & -0.079 & {$[-0.276,0.124]$} & 0.009 & 51 \\
\hline Employment of foreign MNCs & -0.010 & {$[-0.033,0.011]$} & 0.008 & 51 \\
\hline Imports share of GSP & 0.011 & {$[-0.019,0.042]$} & 0.008 & 51 \\
\hline Poverty rates & 0.033 & {$[-0.060,0.126]$} & 0.006 & 51 \\
\hline State tax rates & -0.077 & {$[-0.530,0.382]$} & 0.005 & 51 \\
\hline Mortgage debt per capita & -0.008 & {$[-0.040,0.024]$} & 0.003 & 51 \\
\hline Average temperature & 0.007 & {$[-0.027,0.042]$} & 0.002 & 48 \\
\hline Rate of natural increase & 0.027 & {$[-0.131,0.185]$} & 0.002 & 51 \\
\hline GSP share of US GDP & 0.028 & {$[-0.073,0.125]$} & 0.002 & 51 \\
\hline Agriculture share of GSP & -0.028 & {$[-0.206,0.149]$} & 0.001 & 51 \\
\hline Prisoners per capita & -0.005 & {$[-0.300,0.300]$} & 0.000 & 50 \\
\hline FIRE share of GSP & -0.001 & {$[-0.062,0.057]$} & 0.000 & 51 \\
\hline \multicolumn{5}{|c|}{ CS regression for variables selected by OCMT } \\
\hline & $\hat{\beta}$ & Conf. int. & & \\
\hline Construction share of GSP & 0.092 & {$[-0.436,0.626]$} & & \\
\hline Population growth & -0.801 & {$[-2.003,0.387]$} & & \\
\hline Net migration & 0.218 & {$[0.086,0.348]$} & & \\
\hline Building permits & 0.045 & {$[-0.527,0.627]$} & & \\
\hline NonBusiness bankruptcies & 0.008 & {$[0.003,0.012]$} & & \\
\hline Per capita personal income & 0.002 & {$[-0.082,0.088]$} & & \\
\hline adjusted $R^{2}$ & 0.448 & & & \\
\hline$n$ & 51 & & & \\
\hline
\end{tabular}

Notes: The dependent variable is the four-quarter cumulative impact of the global output shock, scaled by 1000 . Confidence intervals in square brackets are the $90 \%$ intervals. Constant is included in all regressions (not reported). Definitions of individual regressors and their regional availability is provided in Appendix. OCMT selection procedure is applied to all state-level indicators using critical value function with $p=10 \%, \delta=1$ and $\delta^{*}=2$. 
Table A5: Explaining state heterogeneity in the four-quarter cumulative impacts of U.S. national output shock on state employment

\begin{tabular}{|c|c|c|c|c|}
\hline \multicolumn{5}{|c|}{ Net effect coefficient estimates } \\
\hline (Regressors ordered based on $R^{2}$ ) & $\hat{\theta}$ & Conf. int. & $R^{2}$ & $n$ \\
\hline Employment of foreign MNCs & 0.043 & {$[0.024,0.062]$} & 0.176 & 51 \\
\hline Population growth & 0.720 & {$[0.389,1.045]$} & 0.172 & 51 \\
\hline Net migration & 0.094 & {$[0.047,0.141]$} & 0.158 & 51 \\
\hline Agriculture share of GSP & -0.266 & {$[-0.367,-0.163]$} & 0.143 & 51 \\
\hline Government debt share of GSP & 0.108 & {$[0.031,0.183]$} & 0.088 & 51 \\
\hline Govt. share of GSP & -0.087 & {$[-0.134,-0.039]$} & 0.088 & 51 \\
\hline Education (18-24) no highsch & 0.105 & {$[-0.004,0.216]$} & 0.061 & 51 \\
\hline Auto debt per capita & 0.664 & {$[0.005,1.350]$} & 0.059 & 51 \\
\hline W\&R trade share of GSP & 0.132 & {$[-0.010,0.272]$} & 0.053 & 51 \\
\hline Population density & 0.000 & {$[0.000,0.000]$} & 0.053 & 51 \\
\hline Building permits & 0.326 & {$[-0.021,0.683]$} & 0.047 & 51 \\
\hline Real GSP per capita & 0.000 & {$[0.000,0.000]$} & 0.045 & 51 \\
\hline Construction share of GSP & 0.287 & {$[-0.067,0.648]$} & 0.045 & 51 \\
\hline Poverty rates & -0.076 & {$[-0.158,0.006]$} & 0.040 & 51 \\
\hline Credit card debt per capita & 0.577 & {$[-0.089,1.242]$} & 0.040 & 51 \\
\hline Manufacturing share of GSP & 0.043 & {$[-0.013,0.099]$} & 0.039 & 51 \\
\hline Imports share of GSP & 0.022 & {$[-0.011,0.054]$} & 0.039 & 51 \\
\hline NonBusiness bankruptcies & 0.005 & {$[0.000,0.010]$} & 0.037 & 51 \\
\hline Average precipitation & 0.201 & {$[-0.111,0.509]$} & 0.036 & 48 \\
\hline Mining share of GSP & -0.041 & {$[-0.107,0.025]$} & 0.031 & 51 \\
\hline Education (18-24) college & -0.066 & {$[-0.151,0.018]$} & 0.031 & 51 \\
\hline Business bankruptcies & -0.054 & {$[-0.126,0.021]$} & 0.028 & 51 \\
\hline Prisoners per capita & 0.150 & {$[-0.107,0.409]$} & 0.026 & 50 \\
\hline Economic freedom index & 0.312 & {$[-0.196,0.814]$} & 0.025 & 50 \\
\hline Average temperature & 0.024 & {$[-0.015,0.062]$} & 0.025 & 48 \\
\hline State tax rates & -0.156 & {$[-0.415,0.099]$} & 0.024 & 51 \\
\hline Homeownership rate & 0.031 & {$[-0.021,0.086]$} & 0.023 & 51 \\
\hline MVehicle registrations & -0.001 & {$[-0.004,0.001]$} & 0.019 & 51 \\
\hline Exports share of GSP & 0.048 & {$[-0.056,0.151]$} & 0.018 & 51 \\
\hline TPU share of GSP & -0.096 & {$[-0.352,0.162]$} & 0.016 & 51 \\
\hline FIRE share of GSP & 0.029 & {$[-0.019,0.079]$} & 0.015 & 51 \\
\hline Employment tied to exports & 0.077 & {$[-0.095,0.249]$} & 0.015 & 50 \\
\hline Education $(25+)$ college & -0.024 & {$[-0.080,0.033]$} & 0.012 & 51 \\
\hline Mortgage debt per capita & 0.014 & {$[-0.020,0.048]$} & 0.011 & 51 \\
\hline Herfindahl index (product) & -0.001 & {$[-0.003,0.001]$} & 0.009 & 50 \\
\hline Services share of GSP & -0.070 & {$[-0.215,0.076]$} & 0.009 & 51 \\
\hline MVehicle miles traveled per capita & -0.052 & {$[-0.244,0.135]$} & 0.005 & 51 \\
\hline Interstate imports share of GSP & 0.005 & {$[-0.013,0.023]$} & 0.005 & 51 \\
\hline Rate of natural increase & -0.031 & {$[-0.144,0.082]$} & 0.004 & 51 \\
\hline Median home values & -0.001 & {$[-0.006,0.004]$} & 0.004 & 51 \\
\hline GSP share of US GDP & 0.030 & {$[-0.058,0.119]$} & 0.003 & 51 \\
\hline Taxes per capita & -0.080 & {$[-0.399,0.239]$} & 0.003 & 51 \\
\hline Education $(25+)$ no highsch & 0.032 & {$[-0.114,0.179]$} & 0.002 & 51 \\
\hline Cooling degree days & 0.000 & {$[0.000,0.000]$} & 0.002 & 51 \\
\hline Interstate exports share of GSP & 0.002 & {$[-0.013,0.017]$} & 0.001 & 51 \\
\hline Per capita personal income & -0.006 & {$[-0.063,0.049]$} & 0.001 & 51 \\
\hline Heating degree days & 0.000 & {$[0.000,0.000]$} & 0.001 & 51 \\
\hline Herfindahl index (destination) & 0.000 & {$[-0.005,0.005]$} & 0.000 & 50 \\
\hline \multicolumn{5}{|c|}{ CS regression for variables selected by OCMT } \\
\hline \multicolumn{5}{|c|}{ Conf. int. } \\
\hline Population growth & 0.808 & {$[0.508,1.109]$} & & \\
\hline Employment of foreign MNCs & 0.048 & {$[0.031,0.065]$} & & \\
\hline \multirow[t]{2}{*}{ adjusted $R^{2}$} & 0.350 & & & \\
\hline & 51 & & & \\
\hline
\end{tabular}

Notes: The dependent variable is the four-quarter cumulative impact of the U.S. national output shock, scaled by 1000. Confidence intervals in square brackets are the $90 \%$ intervals. Constant is included in all regressions (not reported). Definitions of individual regressors and their regional availability is provided in Appendix. OCMT selection procedure is applied to all state-level indicators using critical value function with $p=10 \%, \delta=1$ and $\delta^{*}=2$. 
Table A6: Explaining state heterogeneity in the four-quarter cumulative impacts of U.S. national employment shock on state employment

\begin{tabular}{|c|c|c|c|c|}
\hline \multicolumn{5}{|c|}{ Net effect coefficient estimates } \\
\hline (Regressors ordered based on $R^{2}$ ) & $\hat{\theta}$ & Conf. int. & $R^{2}$ & $n$ \\
\hline Net migration & 0.171 & {$[0.117,0.224]$} & 0.335 & 51 \\
\hline Population growth & 1.117 & {$[0.693,1.515]$} & 0.265 & 51 \\
\hline Government share of GSP & -0.176 & {$[-0.220,-0.130]$} & 0.232 & 51 \\
\hline Building permits & 0.760 & {$[0.386,1.145]$} & 0.163 & 51 \\
\hline NonBusiness bankruptcies & 0.012 & {$[0.006,0.019]$} & 0.146 & 51 \\
\hline Employment of foreign MNCs & 0.048 & {$[0.024,0.072]$} & 0.138 & 51 \\
\hline Agriculture share of GSP & -0.324 & {$[-0.479,-0.168]$} & 0.136 & 51 \\
\hline Manufacturing share of GSP & 0.099 & {$[0.030,0.167]$} & 0.133 & 51 \\
\hline Education (18-24) no highsch & 0.190 & {$[0.048,0.330]$} & 0.127 & 51 \\
\hline Real GSP per capita & 0.000 & {$[0.000,0.000]$} & 0.119 & 51 \\
\hline Population density & 0.000 & {$[0.000,0.000]$} & 0.115 & 51 \\
\hline W\& $\mathrm{R}$ trade share of GSP & 0.237 & {$[0.083,0.390]$} & 0.111 & 51 \\
\hline Mining share of GSP & -0.091 & {$[-0.139,-0.043]$} & 0.102 & 51 \\
\hline Construction share of GSP & 0.502 & {$[-0.031,1.045]$} & 0.088 & 51 \\
\hline Imports share of GSP & 0.041 & {$[0.003,0.080]$} & 0.087 & 51 \\
\hline TPU share of GSP & -0.240 & {$[-0.466,-0.007]$} & 0.063 & 51 \\
\hline Education (18-24) college & -0.117 & {$[-0.235,0.001]$} & 0.063 & 51 \\
\hline Economic freedom index & 0.584 & {$[0.097,1.067]$} & 0.062 & 50 \\
\hline Auto debt per capita & 0.809 & {$[-0.104,1.690]$} & 0.056 & 51 \\
\hline Average temperature & 0.044 & {$[0.000,0.088]$} & 0.054 & 48 \\
\hline FIRE share of GSP & 0.064 & {$[0.008,0.121]$} & 0.048 & 51 \\
\hline Exports share of GSP & 0.098 & {$[-0.025,0.223]$} & 0.048 & 51 \\
\hline Heating degree days & 0.000 & {$[0.000,0.000]$} & 0.047 & 51 \\
\hline Homeownership rate & 0.054 & {$[-0.026,0.133]$} & 0.043 & 51 \\
\hline Prisoners per capita & 0.223 & {$[-0.055,0.508]$} & 0.040 & 50 \\
\hline GSP share of US GDP & 0.132 & {$[0.020,0.240]$} & 0.039 & 51 \\
\hline Education $(25+)$ college & -0.053 & {$[-0.129,0.022]$} & 0.039 & 51 \\
\hline Government debt share of GSP & 0.079 & {$[-0.023,0.182]$} & 0.031 & 51 \\
\hline Education $(25+)$ no highsch & 0.155 & {$[-0.017,0.326]$} & 0.027 & 51 \\
\hline Herfindahl index (product) & -0.002 & {$[-0.004,0.000]$} & 0.025 & 50 \\
\hline Poverty rates & -0.074 & {$[-0.177,0.028]$} & 0.025 & 51 \\
\hline Herfindahl index (destination) & -0.003 & {$[-0.010,0.004]$} & 0.025 & 50 \\
\hline Motor vehicle registrations & -0.002 & {$[-0.006,0.002]$} & 0.024 & 51 \\
\hline Per capita personal income & -0.045 & {$[-0.121,0.030]$} & 0.022 & 51 \\
\hline Interstate exports share of GSP & 0.011 & {$[-0.008,0.029]$} & 0.022 & 51 \\
\hline Median home values & -0.003 & {$[-0.009,0.003]$} & 0.017 & 51 \\
\hline Interstate imports share of GSP & 0.012 & {$[-0.010,0.033]$} & 0.017 & 51 \\
\hline Mortgage debt per capita & 0.019 & {$[-0.026,0.066]$} & 0.014 & 51 \\
\hline Average precipitation & 0.105 & {$[-0.306,0.529]$} & 0.007 & 48 \\
\hline Employment tied to exports & 0.057 & {$[-0.145,0.257]$} & 0.005 & 50 \\
\hline State tax rates & -0.075 & {$[-0.390,0.240]$} & 0.004 & 51 \\
\hline Cooling degree days & 0.000 & {$[0.000,0.001]$} & 0.003 & 51 \\
\hline Taxes per capita & -0.091 & {$[-0.512,0.336]$} & 0.002 & 51 \\
\hline Credit card debt per capita & 0.166 & {$[-0.604,0.949]$} & 0.002 & 51 \\
\hline Business bankruptcies & 0.018 & {$[-0.089,0.128]$} & 0.002 & 51 \\
\hline Rate of natural increase & 0.015 & {$[-0.101,0.133]$} & 0.001 & 51 \\
\hline MVehicle miles traveled per capita & 0.017 & {$[-0.233,0.257]$} & 0.000 & 51 \\
\hline Services share of GSP & 0.007 & {$[-0.194,0.207]$} & 0.000 & 51 \\
\hline \multicolumn{5}{|c|}{ CS regression for variables selected by OCMT } \\
\hline \multicolumn{3}{|r|}{ Conf. int. } & & \\
\hline Agriculture share of GSP & -0.418 & {$[-0.523,-0.314]$} & & \\
\hline Government share of GSP & -0.164 & {$[-0.211,-0.119]$} & & \\
\hline Population growth & 0.190 & {$[-0.467,0.831]$} & & \\
\hline Net migration & 0.047 & {$[-0.068,0.166]$} & & \\
\hline Building permits & 0.613 & {$[0.185,1.056]$} & & \\
\hline \multirow[t]{2}{*}{ adjusted $R^{2}$} & 0.616 & & & \\
\hline & 51 & & & \\
\hline
\end{tabular}

Notes: The dependent variable is the four-quarter cumulative impact of the U.S. national employment shock, scaled by 1000 . Confidence intervals in square brackets are the $90 \%$ intervals. Constant is included in all regressions (not reported). Definitions of individual regressors and their regional availability is provided in Appendix. OCMT selection procedure is applied to all state-level indicators using critical value function with $p=10 \%, \delta=1$ and $\delta^{*}=2$. 
Table A7: Explaining MSA heterogeneity in the four-quarter cumulative impacts of global output shock on MSA employment

\begin{tabular}{|c|c|c|c|c|}
\hline \multicolumn{5}{|c|}{ Net effect coefficient estimates } \\
\hline (Regressors ordered based on $R^{2}$ ) & $\hat{\theta}$ & Conf. int. & $R^{2}$ & $n$ \\
\hline Education (18-24) no highsch & 0.126 & {$[0.083,0.168]$} & 0.103 & 383 \\
\hline Net migration & 0.074 & {$[0.038,0.110]$} & 0.068 & 365 \\
\hline Education (18-24) college & -0.147 & {$[-0.195,-0.097]$} & 0.053 & 383 \\
\hline Education $(25+)$ college & -0.047 & {$[-0.069,-0.025]$} & 0.034 & 383 \\
\hline Population growth & 0.326 & {$[0.108,0.545]$} & 0.029 & 374 \\
\hline Exports share of GDP & 0.026 & {$[0.005,0.046]$} & 0.014 & 342 \\
\hline Business bankruptcies & 0.177 & {$[0.023,0.334]$} & 0.013 & 364 \\
\hline Poverty rates & -0.039 & {$[-0.064,-0.014]$} & 0.013 & 372 \\
\hline Real GDP growth & 0.174 & {$[-0.065,0.415]$} & 0.009 & 365 \\
\hline Education $(25+)$ no highsch & 0.051 & {$[0.001,0.101]$} & 0.007 & 383 \\
\hline NonBusiness bankruptcies & 0.003 & {$[0.000,0.007]$} & 0.007 & 365 \\
\hline Median home values & 0.001 & {$[0.000,0.003]$} & 0.002 & 361 \\
\hline Per capita personal income & 0.013 & {$[-0.039,0.065]$} & 0.001 & 365 \\
\hline Real GSP per capita & -0.003 & {$[-0.019,0.013]$} & 0.000 & 364 \\
\hline Building permits & 0.014 & {$[-0.090,0.119]$} & 0.000 & 364 \\
\hline GDP share of US GDP & 0.013 & {$[-0.127,0.153]$} & 0.000 & 365 \\
\hline \multicolumn{5}{|c|}{ CS regression featuring all indicators } \\
\hline & $\hat{\beta}$ & Conf. int. & & \\
\hline Exports share of GDP & 0.041 & {$[0.020,0.062]$} & & \\
\hline Real GDP growth & -0.011 & {$[-0.410,0.373]$} & & \\
\hline GDP share of US GDP & 0.004 & {$[-0.199,0.207]$} & & \\
\hline Real GSP per capita & 0.052 & {$[0.011,0.092]$} & & \\
\hline Population growth & -0.191 & {$[-0.454,0.070]$} & & \\
\hline Net migration & 0.106 & {$[0.056,0.153]$} & & \\
\hline Business bankruptcies & 0.136 & {$[-0.043,0.315]$} & & \\
\hline NonBusiness bankruptcies & 0.000 & {$[-0.004,0.004]$} & & \\
\hline Building permits & -0.051 & {$[-0.178,0.082]$} & & \\
\hline Education (18-24) no highsch & 0.046 & {$[-0.042,0.133]$} & & \\
\hline Education (18-24) college & -0.075 & {$[-0.191,0.043]$} & & \\
\hline Education $(25+)$ no highsch & -0.067 & {$[-0.166,0.034]$} & & \\
\hline Education $(25+)$ college & -0.051 & {$[-0.103,0.001]$} & & \\
\hline Per capita personal income & -0.077 & {$[-0.159,0.007]$} & & \\
\hline Median home values & 0.002 & {$[-0.001,0.004]$} & & \\
\hline Poverty rates & -0.041 & {$[-0.104,0.022]$} & & \\
\hline \multirow[t]{2}{*}{ adjusted $R^{2}$} & 0.158 & & & \\
\hline & 335 & & & \\
\hline
\end{tabular}

Notes: The dependent variable is the four-quarter cumulative impact of the global output shock, scaled by 1000 . Confidence intervals in square brackets are the $90 \%$ intervals. Constant is included in all regressions (not reported). Definitions of individual regressors and their regional availability is provided in Appendix. 
Table A8: Explaining MSA heterogeneity in the four-quarter cumulative impacts of U.S. national output shock on MSA employment

\begin{tabular}{|c|c|c|c|c|}
\hline \multicolumn{5}{|c|}{ Net effect coefficient estimates } \\
\hline (Regressors ordered based on $R^{2}$ ) & $\hat{\theta}$ & Conf. int. & $R^{2}$ & $n$ \\
\hline Net migration & 0.065 & {$[0.044,0.085]$} & 0.075 & 365 \\
\hline NonBusiness bankruptcies & 0.007 & {$[0.004,0.009]$} & 0.048 & 365 \\
\hline Business bankruptcies & 0.272 & {$[0.151,0.387]$} & 0.045 & 364 \\
\hline Population growth & 0.326 & {$[0.171,0.476]$} & 0.041 & 374 \\
\hline Education (18-24) no highsch & 0.054 & {$[0.022,0.087]$} & 0.028 & 383 \\
\hline Median home values & 0.003 & {$[0.002,0.004]$} & 0.022 & 361 \\
\hline Per capita personal income & -0.038 & {$[-0.083,0.009]$} & 0.016 & 365 \\
\hline GDP share of US GDP & 0.274 & {$[0.109,0.439]$} & 0.011 & 365 \\
\hline Real GDP growth & -0.160 & {$[-0.343,0.032]$} & 0.010 & 365 \\
\hline Education $(25+)$ no highsch & -0.047 & {$[-0.094,0.002]$} & 0.009 & 383 \\
\hline Poverty rates & 0.026 & {$[-0.002,0.052]$} & 0.008 & 372 \\
\hline Exports share of GDP & -0.010 & {$[-0.024,0.004]$} & 0.003 & 342 \\
\hline Education $(25+)$ college & 0.009 & {$[-0.009,0.028]$} & 0.002 & 383 \\
\hline Building permits & 0.025 & {$[-0.104,0.153]$} & 0.001 & 364 \\
\hline Real GSP per capita & -0.003 & {$[-0.016,0.010]$} & 0.000 & 364 \\
\hline Education (18-24) college & 0.001 & {$[-0.040,0.040]$} & 0.000 & 383 \\
\hline \multicolumn{5}{|c|}{ CS regression featuring all indicators } \\
\hline & $\hat{\beta}$ & Conf. int. & & \\
\hline Exports share of GDP & 0.009 & {$[-0.006,0.023]$} & & \\
\hline Real GDP growth & -0.332 & {$[-0.597,-0.072]$} & & \\
\hline GDP share of US GDP & 0.246 & {$[0.034,0.454]$} & & \\
\hline Real GSP per capita & 0.016 & {$[-0.013,0.045]$} & & \\
\hline Population growth & 0.130 & {$[-0.093,0.357]$} & & \\
\hline Net migration & 0.068 & {$[0.030,0.104]$} & & \\
\hline Business bankruptcies & 0.100 & {$[-0.016,0.215]$} & & \\
\hline NonBusiness bankruptcies & 0.005 & {$[0.001,0.008]$} & & \\
\hline Building permits & -0.016 & {$[-0.177,0.149]$} & & \\
\hline Education (18-24) no highsch & 0.058 & {$[-0.003,0.118]$} & & \\
\hline Education (18-24) college & 0.060 & {$[-0.026,0.149]$} & & \\
\hline Education $(25+)$ no highsch & -0.091 & {$[-0.173,-0.010]$} & & \\
\hline Education $(25+)$ college & -0.009 & {$[-0.045,0.028]$} & & \\
\hline Per capita personal income & -0.062 & {$[-0.131,0.008]$} & & \\
\hline Median home values & 0.003 & {$[0.001,0.005]$} & & \\
\hline Poverty rates & -0.025 & {$[-0.078,0.030]$} & & \\
\hline adjusted $R^{2}$ & 0.221 & & & \\
\hline$n$ & 335 & & & \\
\hline
\end{tabular}

Notes: The dependent variable is the four-quarter cumulative impact of the U.S. national output shock, scaled by 1000. Confidence intervals in square brackets are the $90 \%$ intervals. Constant is included in all regressions (not reported). Definitions of individual regressors and their regional availability is provided in Appendix. 
Table A9: Explaining MSA heterogeneity in the four-quarter cumulative impacts of U.S. national employment shock on MSA employment

\begin{tabular}{|c|c|c|c|c|}
\hline \multicolumn{5}{|c|}{ Net effect coefficient estimates } \\
\hline (Regressors ordered based on $R^{2}$ ) & $\hat{\theta}$ & Conf. int. & $R^{2}$ & $n$ \\
\hline Net migration & 0.093 & {$[0.070,0.116]$} & 0.118 & 365 \\
\hline Population growth & 0.419 & {$[0.237,0.601]$} & 0.052 & 374 \\
\hline Median home values & 0.005 & {$[0.003,0.007]$} & 0.048 & 361 \\
\hline GDP share of US GDP & 0.633 & {$[0.312,0.957]$} & 0.044 & 365 \\
\hline Education (18-24) no highsch & 0.062 & {$[0.028,0.096]$} & 0.028 & 383 \\
\hline Education $(25+)$ college & 0.041 & {$[0.021,0.060]$} & 0.027 & 383 \\
\hline Business bankruptcies & 0.227 & {$[0.086,0.366]$} & 0.024 & 364 \\
\hline Real GSP per capita & 0.027 & {$[0.011,0.042]$} & 0.021 & 364 \\
\hline Education (18-24) college & 0.076 & {$[0.028,0.120]$} & 0.016 & 383 \\
\hline Poverty rates & -0.035 & {$[-0.058,-0.012]$} & 0.011 & 372 \\
\hline NonBusiness bankruptcies & 0.003 & {$[0.000,0.006]$} & 0.009 & 365 \\
\hline Education $(25+)$ no highsch & -0.037 & {$[-0.088,0.013]$} & 0.004 & 383 \\
\hline Per capita personal income & 0.013 & {$[-0.030,0.055]$} & 0.001 & 365 \\
\hline Real GDP growth & 0.044 & {$[-0.128,0.216]$} & 0.001 & 365 \\
\hline Exports share of GDP & 0.004 & {$[-0.019,0.027]$} & 0.000 & 342 \\
\hline Building permits & 0.014 & {$[-0.107,0.134]$} & 0.000 & 364 \\
\hline \multicolumn{5}{|c|}{ CS regression featuring all indicators } \\
\hline & $\hat{\beta}$ & Conf. int. & & \\
\hline Exports share of GDP & 0.027 & {$[0.008,0.047]$} & & \\
\hline Real GDP growth & -0.271 & {$[-0.528,-0.020]$} & & \\
\hline GDP share of US GDP & 0.304 & {$[0.041,0.560]$} & & \\
\hline Real GSP per capita & 0.047 & {$[0.013,0.081]$} & & \\
\hline Population growth & -0.066 & {$[-0.280,0.153]$} & & \\
\hline Net migration & 0.116 & {$[0.078,0.155]$} & & \\
\hline Business bankruptcies & 0.163 & {$[0.029,0.291]$} & & \\
\hline NonBusiness bankruptcies & 0.005 & {$[0.002,0.009]$} & & \\
\hline Building permits & -0.053 & {$[-0.170,0.067]$} & & \\
\hline Education (18-24) no highsch & 0.074 & {$[0.015,0.134]$} & & \\
\hline Education (18-24) college & 0.101 & {$[-0.006,0.209]$} & & \\
\hline Education $(25+)$ no highsch & -0.090 & {$[-0.170,-0.010]$} & & \\
\hline Education $(25+)$ college & -0.006 & {$[-0.047,0.037]$} & & \\
\hline Per capita personal income & -0.072 & {$[-0.153,0.009]$} & & \\
\hline Median home values & 0.003 & {$[0.001,0.006]$} & & \\
\hline Poverty rates & 0.000 & {$[-0.063,0.062]$} & & \\
\hline adjusted $R^{2}$ & 0.211 & & & \\
\hline$n$ & 335 & & & \\
\hline
\end{tabular}

Notes: The dependent variable is the four-quarter cumulative impact of the U.S. national employment shock, scaled by 1000 . Confidence intervals in square brackets are the $90 \%$ intervals. Constant is included in all regressions (not reported). Definitions of individual regressors and their regional availability is provided in Appendix. 